\title{
Moored surface buoy observations of the diurnal warm layer
}

\author{
J. Prytherch, ${ }^{1}$ J. T. Farrar, ${ }^{2}$ and R. A. Weller ${ }^{2}$ \\ Received 27 November 2012; revised 9 August 2013; accepted 13 August 2013; published 13 September 2013.
}

[1] An extensive data set is used to examine the dynamics of diurnal warming in the upper ocean. The data set comprises more than 4700 days of measurements at five sites in the tropics and subtropics, obtained from surface moorings equipped to make comprehensive meteorological, incoming solar and infrared radiation, and high-resolution subsurface temperature (and, in some cases, velocity) measurements. The observations, which include surface warmings of up to $3.4^{\circ} \mathrm{C}$, are compared with a selection of existing models of the diurnal warm layer (DWL). A simple one-layer physical model is shown to give a reasonable estimate of both the magnitude of diurnal surface warming (model-observation correlation 0.88 ) and the structure and temporal evolution of the DWL. Novel observations of velocity shear obtained during 346 days at one site, incorporating high-resolution $(1 \mathrm{~m})$ upper ocean (5-15 m) acoustic Doppler current profile measurements, are also shown to be in reasonable agreement with estimates from the physical model (daily maximum shear model-observation correlation 0.77). Physics-based improvements to the one-layer model (incorporation of rotation and freshwater terms) are discussed, though they do not provide significant improvements against the observations reported here. The simplicity and limitations of the physical model are used to discuss DWL dynamics. The physical model is shown to give better model performance under the range of forcing conditions experienced across the five sites than the more empirical models.

Citation: Prytherch, J., J. T. Farrar, and R. A. Weller (2013), Moored surface buoy observations of the diurnal warm layer, J. Geophys. Res. Oceans, 118, 4553-4569, doi:10.1002/jgrc.20360.

\section{Introduction}

[2] Sea surface temperature (SST) is a key variable in both atmospheric and oceanic dynamics. The interfacial temperature exerts a profound influence on air-sea transfer processes, for example heat and gas fluxes [e.g., Fairall et al., 1996b; Ward et al., 2004]. In situ SST measurements have been collected for more than a century from ships, and more recently from moored and drifting buoys. These measurements are typically made at depths between 1 and $10 \mathrm{~m}$. Since the $1980 \mathrm{~s}$, infrared and microwave radiometers aboard satellites have been used to obtain SST estimates over the majority of the world's oceans. The SST measured by infrared or microwave instruments is the temperature at a depth of approximately 10-20 $\mu \mathrm{m}$ or approximately $20 \mu \mathrm{m}$ to $1 \mathrm{~mm}$, respectively [e.g., Donlon et al., 2002].

[3] In the upper ocean, nighttime convection and the velocity shear driven by surface stress promote vertical mixing, sometimes leading to the existence of a well-mixed

\footnotetext{
${ }^{1}$ Marine Physics and Ocean Climate, National Oceanography Centre, Southampton, UK

${ }^{2}$ Department of Physical Oceanography, Woods Hole Oceanographic Institution, Woods Hole, Massachusetts, USA.

Corresponding author: J. Prytherch, National Oceanography Centre, Southampton, University of Southampton Waterfront Campus, Southampton SO14 3ZH, UK. (jzp@noc.ac.uk)

(C)2013. American Geophysical Union. All Rights Reserved. 2169-9275/13/10.1002/jgrc.20360
}

surface layer. This mixed layer may extend to $100 \mathrm{~m}$ depth or more. During the day, solar radiation heats the upper ocean. Depending on water clarity, about half of this energy is absorbed within the upper meter [Soloviev and Lukas, 2006]. The net heating can create a stably stratified layer above the nocturnal mixed layer, which we will refer to as the diurnal warm layer (DWL). The heat and momentum input into the DWL by the sun and wind is inhibited from mixing into the relatively uniform layer beneath by the stable stratification. Additionally, cooling in the upper few microns of the ocean due to sensible, latent, and longwave heat loss creates a cool-skin layer, approximately 5 mm thick and $0.1-0.5^{\circ} \mathrm{C}$ cooler than the water below [e.g., Saunders, 1967; Castro et al., 2003]. This cool skin is almost always present in the ocean during both night and day and is in addition to any DWL that may be present.

[4] The competing effects of stably stratifying solar heating and the combination of surface evaporation, cooling, and wind-driven mixing affect both the magnitude of the DWL temperature anomaly and the depth over which the DWL extends. The magnitude of the diurnal SST anomaly is typically a few 10 s of a degree [e.g., Stuart-Menteth et al., 2003; Kennedy et al., 2007], and wind stress-induced mixing can lead to a detectable diurnal temperature anomaly as deep as $60 \mathrm{~m}$ [e.g., Stommel and Woodcock, 1951; Stommel et al., 1969]. Under light winds and strong insolation, when the DWL will typically be confined to the upper few meters, the temperature anomaly can exceed $5^{\circ} \mathrm{C}$ [e.g., Gentemann and Minnett, 2008]. In these conditions, the large temperature gradient within the DWL can lead to 


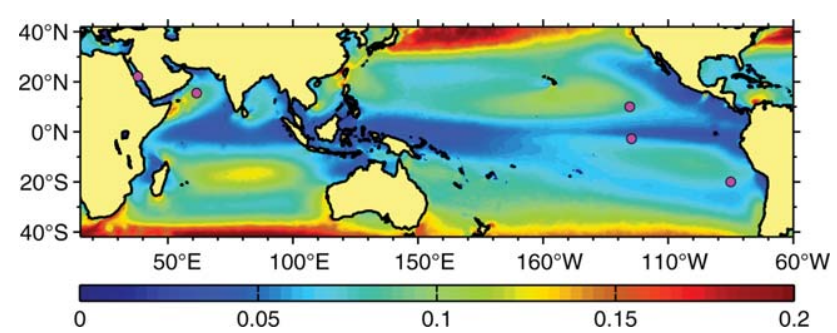

Figure 1. Surface mooring locations (pink dots in eastern Pacific, Arabian Sea, and Red Sea). The color shading indicates the mean wind stress magnitude $\left(\mathrm{kg} \cdot \mathrm{m}^{-1} \cdot \mathrm{s}^{-2}\right)$ from the wind climatology of Risien and Chelton [2008] (based on data from the QuikSCAT scatterometer from 1999 to 2009).

significant differences between temperature measurements made at depths only a meter or two apart.

[5] There are numerous applications in which measurements made at differing depths need to be related to one another, and where the presence of the cool skin and a DWL may thus introduce an error. Ship-based radiometers capable of measuring the temperature close to the interface remain expensive and challenging to employ in open ocean conditions [e.g., Gentemann and Minnett, 2008]. Hence, most in situ measurements of SST are made at some depth below the interface and must be adjusted to account for the DWL and cool-skin effect in order to avoid errors when estimating air-sea fluxes from bulk formulae [Fairall et al., 1996a]. Conversely, ocean surface temperature measurements made by satellite-based infrared and microwave radiometers must be adjusted for applications in which the bulk mixed layer temperature is required (e.g., comparison with, and validation and calibration against, in situ measurements).

[6] A large variety of different measurements of ocean temperature are often referred to as SST [Donlon et al., 2002]. Whilst in situ temperature measurements are necessarily made below the cool skin, they may be within the warm layer, which can extend to several $10 \mathrm{~s}$ of meters depth. We define SST to be a near-surface temperature, often referred to as the bulk SST and measured with an in situ sensor. Where applicable, SST is stated here with the depth of measurement, otherwise SST is the temperature of the shallowest available measurement depth.

[7] A number of models of the DWL have been developed. These include numerical boundary layer models [e.g., Kondo et al., 1979; Price et al., 1986; Large et al., 1994; Kantha and Clayson, 1994; Soloviev et al., 2001], an idealized physical model based on the Price et al. [1986], numerical model with a simplified mixing scheme [Fairall et al., 1996a], and several empirically derived statistical models [e.g., Webster et al., 1996; Kawai and Kawamura, 2002; Gentemann et al., 2003]. In order to fully capture the dynamics of diurnal warming, both surface measurements of wind stress and heat flux, and subsurface measurements of temperature and velocity at high enough spatial and temporal resolutions to resolve the structure and evolution of the DWL are required. These challenging requirements mean that models are usually validated using a data set of limited duration from a partic- ular location under a limited range of environmental conditions [e.g., Price et al., 1986; Fairall et al., 1996a; Gentemann et al., 2009; Kawai and Kawamura, 2002].

[8] We report on a data set of 4712 days of diurnal warming observations made from moored buoys deployed and maintained by the Upper Ocean Processes Group of the Woods Hole Oceanographic Institution at five deep-water sites between October 1994 and December 2010. The data, detailed in section 2 , include hourly measurements of surface meteorology, incident radiation, and subsurface velocity and temperature. These observations span a range of meteorological conditions and exhibit upper ocean diurnal cycles of varying magnitudes, providing an opportunity to examine the subsurface evolution and dynamics of the DWL. These surface moorings were instrumented to recover well-resolved near-surface temperature structure with study of the DWL in mind. For 375 days of observations at one site, we also have Acoustic Doppler Current Profiler (ADCP) measurements of velocity with $1 \mathrm{~m}$ depth resolution at depths of 5-15 $\mathrm{m}$ and other velocity measurements at greater depths.

[9] Two models of the DWL (a simple physical model, Fairall et al. [1996a], referred to henceforth as F96, and a statistical model, Webster et al. [1996], referred to henceforth as W96) are described in section 3 and tested against the data set. The measurements presented in section 4 provide a test of model performance and allow an assessment of the extent to which a simple dynamical model like F96 can be used for gaining physical insight into the dynamics of the DWL (section 5).

\section{Moorings and Instrumentation}

[10] The surface buoys at the five locations (Figure 1 and Table 1) were equipped with two complete sets of meteorological sensors (wind velocity, air and sea temperature, incoming shortwave and incoming longwave radiation, relative humidity, barometric pressure, and precipitation), using redundancy to ensure that complete and accurate time series of all variables were collected, thus permitting calculation of the heat, mass, and momentum fluxes via the bulk formulae. The earlier deployments used a combination of one Vector-Averaging Wind Recorder (VAWR) and one Improved Meteorological System (IMET) while later deployments used two IMET systems as indicated in Table 2. The VAWR is described in Weller et al. [1990]; it did short duration, several second long sampling of the humidity and barometric pressure sensors, 1.875 min sampling of air temperature and sea temperature, averaged shortwave and longwave radiation over $1.875 \mathrm{~min}$, and vectoraveraged wind velocity over the full sample interval and

Table 1. Names, Locations, and Durations of the Five Mooring Sites

\begin{tabular}{lcccc}
\hline Mooring & Latitude & Longitude & Start & End \\
\hline Arabian Sea & $15.5^{\circ} \mathrm{N}$ & $61.5^{\circ} \mathrm{E}$ & Oct 1994 & Oct 1995 \\
PACS North & $10^{\circ} \mathrm{N}$ & $125^{\circ} \mathrm{W}$ & Apr 1997 & Sep 1998 \\
PACS South & $2.7^{\circ} \mathrm{S}$ & $125^{\circ} \mathrm{W}$ & Apr 1997 & Sep 1998 \\
Stratus & $20^{\circ} \mathrm{S}$ & $85^{\circ} \mathrm{W}$ & Oct 2000 & Ongoing \\
KAUST & $22^{\circ} \mathrm{N}$ & $38.5^{\circ} \mathrm{E}$ & Oct 2008 & Dec 2010 \\
\hline
\end{tabular}


Table 2. Meteorological Instruments and Basic Recording Rates

\begin{tabular}{llclc}
\hline Site & System 1 & Recording & System 2 & Recording \\
\hline Arabian Sea & VAWR & $7.5 \mathrm{~min}$ & IMET & $1 \mathrm{~min}$ \\
PACS North & VAWR & $15 \mathrm{~min}$ & IMET & $1 \mathrm{~min}$ \\
PACS South & VAWR & $15 \mathrm{~min}$ & IMET & $1 \mathrm{~min}$ \\
Stratus & IMET & $1 \mathrm{~min}$ & IMET & $1 \mathrm{~min}$ \\
KAUST & IMET & $1 \mathrm{~min}$ & IMET & $1 \mathrm{~min}$ \\
\hline
\end{tabular}

recorded to a digital cassette tape at a basic sampling rate ( 7.5 or $15 \mathrm{~min}$; Table 2). The IMET is discussed by Hosom et al. [1995]; it powers up and samples the scalar sensors several times within $1 \mathrm{~min}$ and then averages those readings while also vector averaging the wind velocity over its 1 min basic sampling rate. Table 3 summarizes the sensor sets typically used with the VAWR and the IMET and the observation heights. The accuracies of the VAWR and IMET meteorological and derived bulk formulae fluxes have been discussed in several publications, including Moyer and Weller [1997] and, most recently, Colbo and Weller [2009]. The goal of both systems was to make near-surface meteorological observations with accuracies sufficient to allow the net heat flux computed using bulk formulae methods to have an accuracy of at least $10 \mathrm{~W}$ $\mathrm{m}^{-2}$ at daily and longer sampling period. Continuing improvements to the systems have been underway. Accuracy in the net heat flux on daily and longer time scales achieved in the Arabian Sea was close to $15 \mathrm{~W} \mathrm{~m}^{-2}$ [Weller et al., 1998], and this accuracy improved to $8 \mathrm{~W}$ $\mathrm{m}^{-2}$ in recent Stratus deployments [Colbo and Weller, 2009]. The additional heat flux (typically, a cooling) associated with rain is computed assuming the rain water enters the ocean at the wet bulb temperature, an assumption tested with direct observations of rain temperature from a buoy in the tropical western Pacific [Anderson et al., 1998].

[11] The bridle legs of the buoy provide the standard location for the sea temperature sensor associated with the VAWR and IMET systems. Additional near-surface temperature sensors were deployed for some moorings and are described below. The mooring line beneath the buoy hulls carried current meters, temperature/conductivity recorders, and more temperature recorders. All temperature recorders were calibrated before and after deployment and were accurate to $0.01^{\circ} \mathrm{C}$ or better.

[12] Raw data collected from the instruments on and below the surface buoy are subject to quality control and used to develop "best basic" time series. All meteorological and ocean temperature/conductivity sensors are calibrated before deployment and after recovery. In addition to predeployment and postdeployment calibrations, meteorological sensors are subject to additional checks. The first postdeployment calibration is done on the sensor in its "as recovered" state, including any environmental impacts (e.g., salt spray, bird droppings). Upon deployment and prior to recovery, the research vessel is positioned close to the surface buoy (nominally $0.25 \mathrm{~nm}$ away), bow into the wind to support intercomparison of the shipboard meteorological sensors and those on the buoy. Whenever possible, the new buoy is deployed 1 or 2 days prior to the recovery of the buoy then in the water; and the data from the overlapping period are examined for any evidence of drift or change in the deployed sensors. The best basic time series of surface meteorology were then used for each deployment to compute the air-sea fluxes following methods described in Weller and Anderson [1996] and using the Tropical Ocean Global Atmosphere (TOGA) Coupled Ocean-Atmosphere Response Experiment (COARE) bulk algorithm [Fairall et al., 2003].

[13] Incoming solar radiation was measured, and outgoing (or reflected) solar radiation was estimated using a constant albedo of 0.06 . Incoming infrared radiation was also measured, and the infrared radiation leaving the sea surface was estimated using the Stephan-Boltzman relation with an emissivity of 0.97 and an estimate of the surface skin temperature computed with the COARE Flux Algorithm. This algorithm provides latent and sensible heat fluxes and wind stress [Fairall et al., 1996b, 2003] and is believed to be accurate to about $5 \%$ for wind stress and

Table 3. Meteorological Sensors, Heights, and Sampling for VAWR and IMET, in This Case, as Deployed in the Arabian Sea

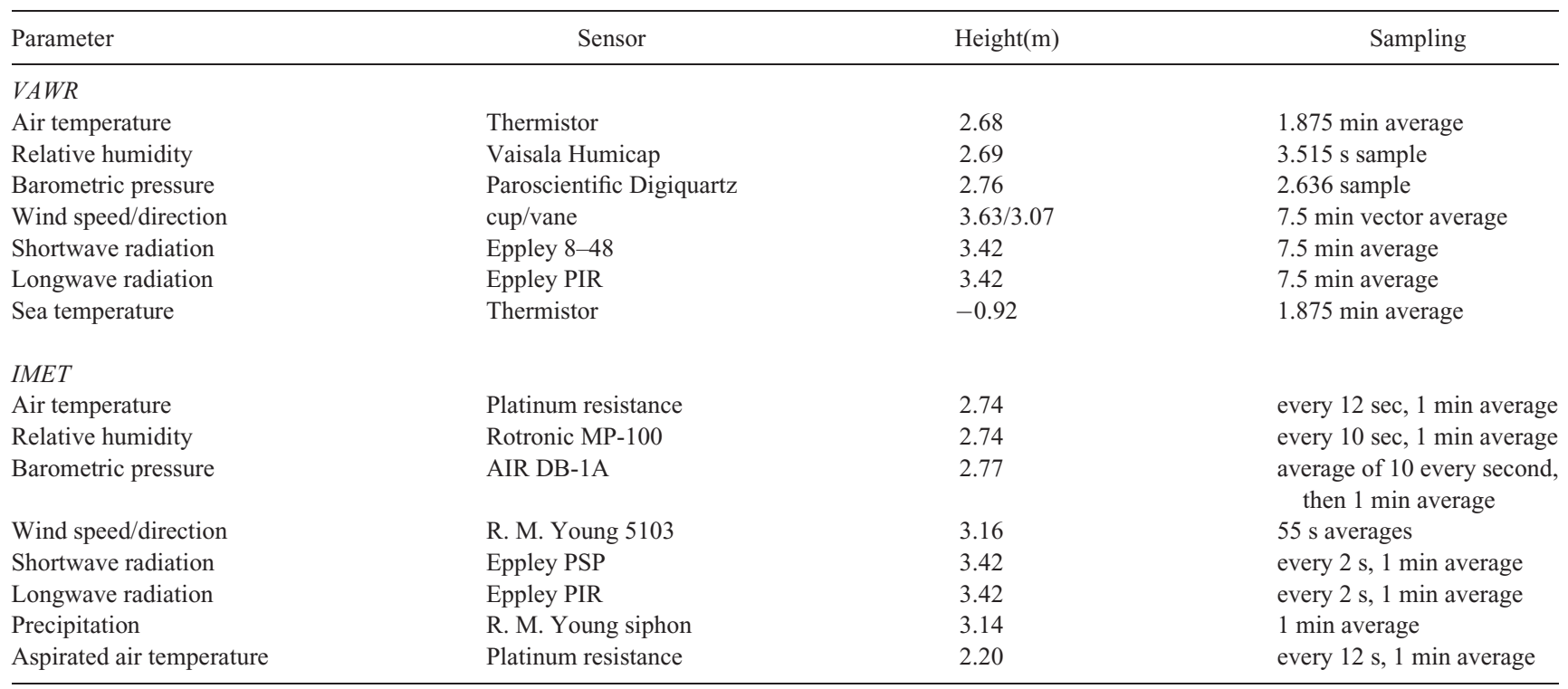


latent heat flux (the largest nonsolar component of the surface heat flux) for wind speeds of up to $10 \mathrm{~m} \mathrm{~s}^{-1}$ [Fairall et al., 2003]. The full TOGA-COARE bulk flux algorithm includes subroutines to estimate the differences between the shallowest measured subsurface temperature and the true skin temperature that result from the cool-skin and warm-layer effects (F96) [Fairall et al., 1996b]. The estimate of the surface skin temperature resulting from application of these corrections to the shallowest measured temperature is then used in the bulk formulas. Because of the interdependence of skin temperature and surface fluxes, the algorithm uses an iterative procedure to find a selfconsistent solution (F96) [Fairall et al., 1996b]. The coolskin correction and the warm-layer correction were applied in making the flux estimates for all five sites. Use of the cool-skin and warm-layer corrections for estimating the surface fluxes does not compromise the independence of our comparison of observed and modeled temperatures because these corrections, meant to "extrapolate" our nearsurface temperature measurements to the air-sea interface, are used only in the context of estimating the surface fluxes.

[14] The buoy structure will distort near-surface flow, and may cause the near-surface instrumentation to measure water from depths shallower than the instrument, potentially causing an apparent low bias in the modeled estimate of surface warming. The magnitude of this flow-distortioninduced horizontal temperature inhomogeneity has been shown to be as large as $1^{\circ} \mathrm{C}$ for a similar buoy design [Kawai et al., 2006]. While Farrar et al. [2007] show an example of generation of a cool wake by a buoy in the presence of a relatively strong diurnal warm layer, we believe that, that the most common effect of flow distortion around the buoy hull is to cause the measured SST to be warmer than the ambient temperature at that depth. Prior to the deployment of the Arabian Sea surface mooring, we had experimented with a taut cable with eight thermistors on a chain deployed roughly $0.2 \mathrm{~m}$ to the side of the hull of the surface buoy, and spanning from near the surface to $2 \mathrm{~m}$ depth. In well-mixed conditions, temperature data from the same depth on the buoy bridle matched that on the thermistor string. However, when the upper 2-3 m was stratified, the bridle temperature was better matched by data from a shallower depth on the thermistor chain, with that depth being roughly equivalent to the distance the bridle sensor was below the bottom of the hull. The preliminary conclusion was that stratified fluid flowed down under the hull, with the result that the bridle sensor would be too warm for its depth.

Some specific details of each deployment are summarized here:

[15] Arabian Sea: the mooring site in the central Arabian Sea $\left(15.5^{\circ} \mathrm{N}, 61.5^{\circ} \mathrm{E}\right)$ was occupied during October 1994 to October 1995 as part of a mixed-layer dynamics process study [Weller et al., 1998, 2002; Fischer et al., 2002]. Diurnal warming was observed during the low-wind periods between the summer and winter monsoons. A major focus in this field study was on resolving processes that controlled SST. As such, six additional temperature recorders were deployed, two off a bracket attached to the buoy hull and four off a bracket attached to the bridle leg, thus forming a vertical array of six temperature recorders on the downwind (on the same side as the wind vane that oriented the buoy) side of the hull. The depths of these sensors were $0.55,0.81,1.30,1.79,2.29$, and $2.78 \mathrm{~m}$ below the waterline of the buoy. The temperature recorders were placed within multiplate radiation shields, similar to those used with air temperature sensors, to prevent direct radiative heating, and they recorded every $15 \mathrm{~min}$. To gauge the utility of the additional temperature sensors deployed close to the hull of the moored buoy, we also deployed surface drifters with small surface expressions and temperature recorders at depths matching those in the array on the side of the surface buoy for the purpose of conducting intercomparison experiments. We targeted 3 days of low wind and strong insolation, deploying the drifting array in the early morning in the vicinity of the surface buoy and recovering at dusk. The drifting temperature records and the moored temperature records from the array alongside the buoy hull showed good agreement over the course of the observed diurnal cycle, with the same depth records agreeing to better than $0.1^{\circ} \mathrm{C}$. We took this as verification of the performance of the alongside temperature array. On the other hand, the temperature sensor beneath the buoy, on the bridle leg was during the day at times warmer than expected, suggesting the stratified near-surface flow dives under the buoy hull. The success of the array mounted alongside the Arabian Sea buoy prompted the use of the same approach in PACS (Figure 2).

[16] Pan American Climate Study (PACS): measurements began in April 1997 when two Woods Hole Oceanographic Institution (WHOI) surface moorings were deployed at $3^{\circ} \mathrm{S}$ and $10^{\circ} \mathrm{N}$ on $125^{\circ} \mathrm{W}$ [Yuter and Houze, 2000; Anderson et al. 2000]. After 8 months, the moorings were recovered and redeployed (December 1997). The moorings were recovered in September 1998. The northern PACS site, referred to here as "PACS North," was chosen to be near the climatological location of the Inter-Tropical Convergence Zone (ITCZ). In broad terms, the meteorological conditions recorded at PACS North varied from deepconvective conditions with periods of weak winds punctuated by squalls, storms, and tropical weather systems to trade wind conditions having clear skies, high evaporation, and steady, sustained winds of $6-10 \mathrm{~m} \cdot \mathrm{s}^{-1}$ as the ITCZ moved north and south in association with its annual cycle in the eastern Pacific. The southern site, referred to here as "PACS South", was chosen to be on the southern flank of the equatorial cold tongue. A strong El Niño event occurred in 1997, leading to anomalously strong atmospheric convection and weak winds at the southern site, particularly during the period of November 1997 to May 1998.

[17] The focus of PACS was largely on surface temperature and the upper ocean response to local atmospheric forcing. One distinguishing characteristic of the PACS moorings is a high density of subsurface instruments for measuring temperature. Each mooring carried about 30 temperature instruments in the upper $100 \mathrm{~m}$, with smaller vertical separation toward the surface [Anderson et al., 2000]. The buoys were fitted with a closely spaced array of temperature recorders with solar shields to resolve diurnal heating near the sea surface (depths of $0.2,0.7,1.2,1.7$, and $2.2 \mathrm{~m}$ for the first deployments and depths of $0.2,0.5$, $1.0,1.5,2.0$, and $2.5 \mathrm{~m}$ for the second deployments of both buoys) and a floating surface temperature sensor at a depth 


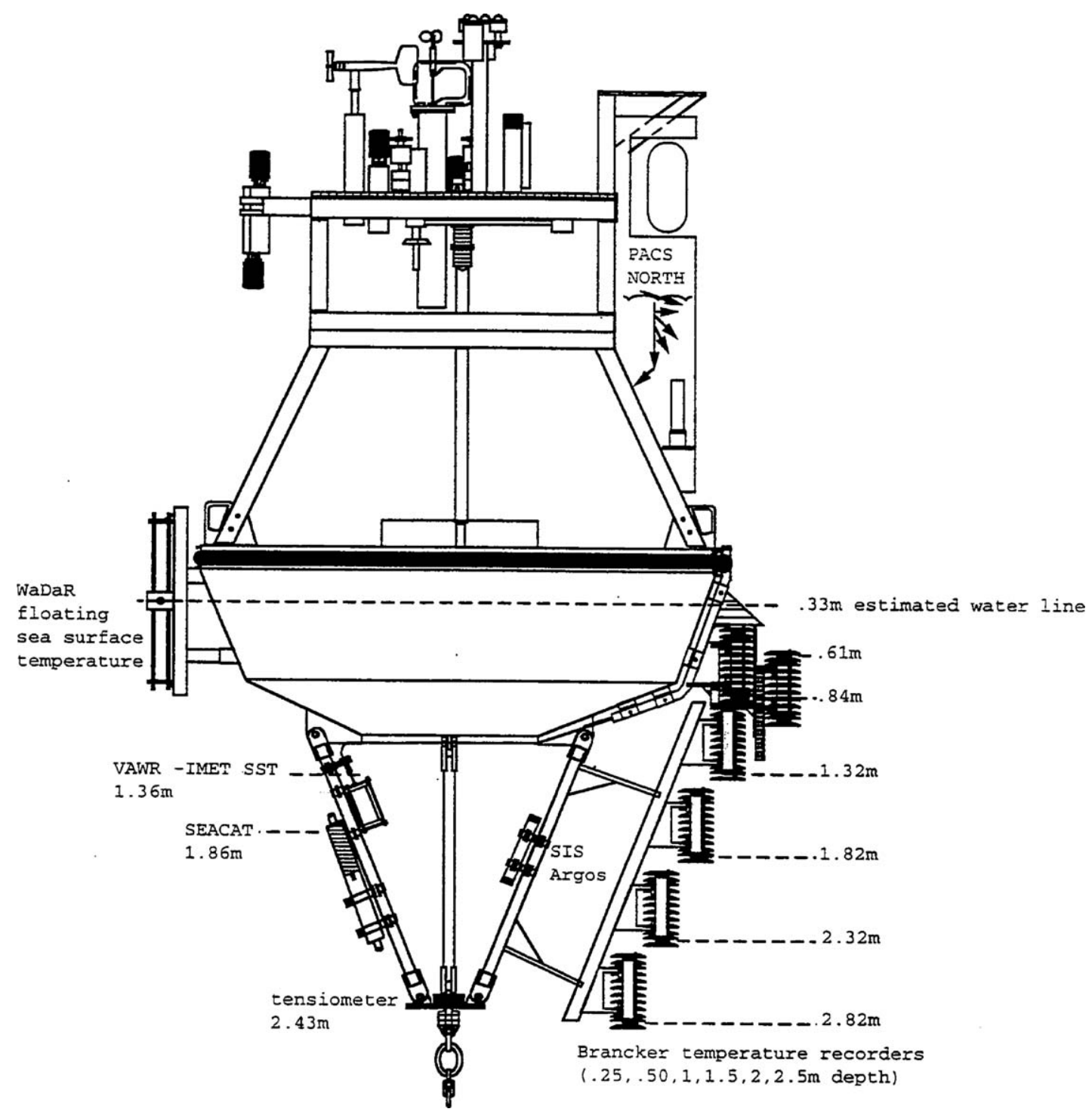

Figure 2. PACS North buoy, with tower and bridle instrumentation as configured for the second deployment.

of about $5 \mathrm{~cm}$ to record SST as close to the surface as possible, with four Seacat conductivity/temperature recorders (at 1, 10, 20, $30 \mathrm{~m}$ ), and 10 Vector Measuring Current Meters (at 5, 10, 15, 20, 30, 40, 50, 70, 90, $110 \mathrm{~m}$ ) which measure horizontal velocity and temperature, and nine Brancker temperature recorders (at 7.5, 12.5, 17.5, 25, 35, $45,60,80$, and $150 \mathrm{~m}$ ). Note that the actual near-surface sensor depths as given here are typically estimated from visual estimates of the water line after deployment and measurement of the mean water line as indicated by biofouling on the buoy after recovery and are accurate to approximately $\pm 5 \mathrm{~cm}$.

[18] Stratus: the mooring off northern Chile $\left(20^{\circ} \mathrm{S}\right.$, $\left.85^{\circ} \mathrm{W}\right)$ under the marine Stratus clouds found in the eastern South Pacific is labeled Stratus. This site has the longest record having been occupied from October 2000 to the present, originally as part of the Eastern Pacific Investigation of Climate (EPIC) [Bretherton et al., 2004] and maintained since then with annual servicing as a NOAA Ocean Refer- ence Station. The 2576 days of data from October 2000 to October 2007 are analyzed here. The site is beneath the expansive Stratus cloud decks of the eastern South Pacific [Colbo and Weller, 2007]. This is a trade wind regime, with winds out of the southeast. The winds do vary in speed, and there are periods of low winds with diurnal restratification.

[19] Because of the aggressive biofouling at Stratus and the labor involved in assembly and then disassembly and cleaning of the multiplate radiation shields used on the temperature sensor arrays alongside the Arabian Sea and PACS buoys, this approach was not used at Stratus. Instead, the floating SST sensor was deployed, supplemented by additional shallow temperature sensors attached directly to the buoy hull at fixed depths. In addition, the Stratus deployment was marked by an effort to better resolve the nearsurface velocity structure, with fixed-depth point current meters and an RDI ADCP looking up at $135 \mathrm{~m}$ being supplemented by deployments of 1 or $2 \mathrm{MHz}$ Nortek ADCPs 
looking up from $15 \mathrm{~m}$ depth. For the 1 year of velocity used here, a $2 \mathrm{MHz}$ Nortek was set up for a $60 \mathrm{~s}$ burst of pings, at $5.25 \mathrm{~Hz}$ (315 pings total), every hour. The Nortek software states the velocity uncertainty is $1.6 \mathrm{~cm} \cdot \mathrm{s}^{-1}$.

[20] Over the decade that the Stratus site has been occupied, the buoy and mooring have been replaced annually, and, hence, the configuration of instruments (particularly subsurface ones) has changed from year-to-year. The buoy design was also changed from a steel-hulled $3 \mathrm{~m}$ discus buoy to the newer WHOI Modular Ocean Buoy System (MOBS) in 2004, which allows a shallower mounting point for the SeaBird SBE-37 SST sensor that is integrated into the IMET system. Although the actual instrument depth depends on the net buoyancy of each buoy with its particular battery/instrument payload and subsurface instrument/ hardware load, the nominal depth of the IMET SST measurement is $1 \mathrm{~m}$ for the older $3 \mathrm{~m}$ discus buoys and $0.5-$ $0.75 \mathrm{~m}$ for the newer MOBS buoys.

[21] KAUST: the mooring site in the central Red Sea $\left(22^{\circ} \mathrm{N}, 38.5^{\circ} \mathrm{E}\right)$ was occupied from October 2008 until December 2010 [Farrar et al., 2009] under a project funded by the King Abdullah University of Science and Technology in Saudi Arabia and is referred to as KAUST. The Red Sea experiences strong insolation, high evaporation, a strong land-sea breeze and intermittent, strong wind events [e.g., Jiang et al., 2009].

[22] For all moorings, further information and links to relevant technical reports, along with most data, can be found at http://uop.whoi.edu.

\section{Modeling}

[23] The F96 model of diurnal warming in the upper ocean is a development of the model described by Price et al. [1986]. The model assumes that the magnitude of diurnal warming is dependent on two competing factors: the surface heat input, which tends to increase the near-surface stratification, and the surface momentum flux, which tends to decrease the near-surface stratification. In the model, when the heating applied to the upper ocean overcomes the mixing effects resulting from wind-driven vertical shear, a stably stratified surface layer (the DWL) is formed. Within the DWL, heat from the sun and momentum from the wind are trapped by the stable stratification, though some solar radiation can penetrate beyond the base of the DWL. Wind stress causes mixing which deepens the DWL down into the mixed layer below.

[24] The F96 model represents the dynamics of temperature and momentum in the upper ocean via onedimensional heat and momentum equations. The model assumes unidirectional winds and currents, neglects horizontal property variations, and temperature and velocity within the layer are assumed to vary linearly with depth. As the depth of the DWL will itself vary, the system is closed by assuming that the base of the DWL, $D_{T}$, referred to as the trapping depth, remains at some critical Richardson number, $R i_{c}$. The critical Richardson number is intended to represent the ratio at which the velocity shear overcomes stratification within the water column, causing mixing. In Price et al. [1986] and F96, $R i_{c}$ is chosen to be 0.65 , and we will use this value in our examination of the model.
[25] The amount of heat absorbed in the DWL is a function of $\delta S_{w}$, the portion of the net shortwave radiation absorbed in the DWL, which is itself dependent on $D_{T}$. For our analysis, the chlorophyll-dependent model of Ohlmann [2003] was used to estimate $\delta S_{w}$. Estimates of chlorophylla concentration, made by NASA's Sea-viewing Wide Field-of-view Sensor (SeaWiFS) satellite mission, were obtained as level-3, mapped data on a monthly, $9 \mathrm{~km}$ grid from NASA's Ocean Color website (http://oceandata.sci.gsfc.nasa.gov/). For periods when monthly mean chlorophyll estimates were not available (6 months at PACS North, 7 months at PACS South, 20 months at Stratus, 5 months at KAUST, and the entire Arabian Sea deployment), a monthly climatological value (SeaWiFS level-3 mapped $9 \mathrm{~km}$ grid) was used instead.

[26] Here and in F96, $D_{T}$ is initialized at $19 \mathrm{~m}$ each day, and the model integration starts when the heat input to the layer (i.e., the upper $19 \mathrm{~m}$ ) becomes positive. The F96 model does not specify at what point integration should be halted, but it seems clear that the integration should be stopped when the heat input to the DWL becomes negative, when convection, a process not considered in the model, will become increasingly important in setting the upper ocean vertical structure (section 5.1).

[27] The F96 model requires estimates of the surface heat fluxes and wind stress that resolve the time period between sunrise and sunset. Such estimates can be readily obtained from ships or buoys, but the largest number of available SST measurements come from satellites equipped with infrared or microwave radiometers, which provide extensive spatial coverage not possible with in situ measurements. While much can be learned about the spatial patterns of diurnal warming by examining differences between SST from daytime and nighttime satellite passes [e.g., Gentemann et al., 2003; Stuart-Menteth et al., 2003], global estimates of the surface heat fluxes and wind stress [e.g., Yu and Weller, 2007] typically do not have the temporal resolution needed to interpret these patterns using a prognostic, dynamical model (such as F96). In lieu of wellresolved time series of each surface forcing term, one can attempt to parameterize the magnitude of the diurnal warming as a function of statistics of the surface forcing, such as the daily mean wind speed and daily maximum insolation. One such model, W96, is employed here.

[28] The W96 model was developed from a modified version of a one-dimensional ocean boundary layer model [Kantha and Clayson, 1994]. A model of the cool-skin layer was added to the boundary layer model, which was tested against in situ data from the TOGA-COARE experiment in the western tropical Pacific. A regression of the model allowed the magnitude of diurnal warming at the sea surface to be related to maximum daily solar insolation, average daily wind speed and average daily precipitation.

\section{Results}

\subsection{Summary of Observations and Models}

[29] In total from the five moorings, 4712 days (out of 4755 complete observation days) had all the necessary measurements required to compare the F96 and W96 models with observation. The magnitude of a particular day's diurnal warming was determined from the shallowest 
Table 4. Diurnal Warming Observations for Each Location ${ }^{\mathrm{a}}$

\begin{tabular}{lccccc}
\hline Buoy Mooring & $\begin{array}{c}\text { Total } \\
\text { Days }\end{array}$ & $\begin{array}{c}\text { Days } \\
\text { Used }\end{array}$ & $\begin{array}{c}\text { SST } \\
\text { Depth }(\mathrm{cm})\end{array}$ & $\begin{array}{c}\text { Mean } \\
\Delta \text { SST }\end{array}$ & $\begin{array}{c}\text { Max } \\
\Delta \text { SST }\end{array}$ \\
\hline Arabian Sea & 367 & 365 & 17 & 0.38 & 2.48 \\
PACS North & 501 & 492 & 25 & 0.30 & 2.25 \\
PACS South & 516 & 497 & 5 & 0.32 & 3.25 \\
Stratus & 2576 & 2576 & $5 / 50$ & 0.23 & 3.38 \\
KAUST & 795 & 782 & 65 & 0.43 & 3.18 \\
All moorings & 4755 & 4712 & & 0.29 & 3.38 \\
\hline
\end{tabular}

${ }^{\mathrm{a}} \Delta \mathrm{SST}$ is the observed surface warming, defined as the difference between the maximum daytime SST and the SST just prior to the formation of the warm layer (as determined by the F96 model).

available temperature measurement, the depth of which varied from 5 to $65 \mathrm{~cm}$ (Table 4). The magnitude of diurnal warming on a given day is defined here as the difference between the maximum daytime SST and the SST at a time just prior to when the heat input to the ocean surface $\delta S_{w}-Q$, where $Q$ is the total cooling at the interface (from latent, sensible, longwave and rain heat fluxes), becomes positive. The time at which the heat input becomes positive is also assumed to be the time at which any DWL begins to form, and in the mooring data presented here, this occurs on average $2.5 \mathrm{~h}$ after local sunrise. The SST measurement depths are all unambiguously below the depth of the cool skin. Although the W96 model includes the cool-skin effect, this is not expected to be a significant source of error since diurnal variations in the cool-skin effect are expected to be small compared to the diurnal variations in the warm layer (W96) [Wick et al., 2005]. The F96 model estimates have been calculated for the depth of the SST observation with which they are compared.

[30] The observed warming (Table 4) was on average $0.29^{\circ} \mathrm{C}$. The highest observed warming of $3.38^{\circ} \mathrm{C}$ was from the Stratus site. Across the five mooring sites there are a total of 221 days where the observed warming exceeded $1^{\circ} \mathrm{C}, 27$ days where it exceeded $2^{\circ} \mathrm{C}$ and 6 days where it exceeded $3^{\circ} \mathrm{C}$. The maximum daytime SST typically occurred between 7 and $11 \mathrm{~h}$ (average $8.25 \mathrm{~h}$ ) after sunrise. The F96 model predicts the observed temperature anomalies with a correlation coefficient of 0.89 or greater at each of the five sites (Table 5 and Figures 3 and 4). The W96 results have a positive bias for warming magnitudes up to around $1.5^{\circ} \mathrm{C}$, so that predicted peak diurnal temperatures were typically higher than both the observations and F96 predictions (Table 6 and Figures 3 and 4). For $\Delta$ SST above $1.5^{\circ} \mathrm{C}$ the W96 model begins to underestimate the warming and the model prediction appears to plateau around $2^{\circ} \mathrm{C}$.

[31] The seasonal dependence of the correlation of modeled and observed daily maximum $\triangle \mathrm{SST}$ is shown in Figure 5. Values are only shown if at least 25 days of measurements were included in the 30 day average, and for the PACS North and South sites, this led to removal of measurements made close to the December mooring changes. Note that Stratus and KAUST are the only data sets with more than 2 years of data. At the Arabian Sea mooring, there is particularly low model-observation correlation between mid June and early September (day of year 165-250). The regional monsoon during this period led to cooling conditions and persistent high winds (average wind speed for this period was $11.0 \pm 2.0 \mathrm{~m} \cdot \mathrm{s}^{-1}$, compared with $5.1 \pm 2.1 \mathrm{~m} \cdot \mathrm{s}^{-1}$ during the rest of the deployment), and the poor model performance is likely due to advection of cooler water (discussed further in section 5.8).

\subsection{Surface Warming and Trapping Depth}

[32] A clear diurnal signal is usually visible in the time series of near-surface temperature recorded at all the sites examined. An example of several consecutive days of moderately large diurnal warming from the PACS North $\left(10^{\circ} \mathrm{N}\right.$, $125^{\circ} \mathrm{W}$ ) buoy serves to illustrate the typical structure and evolution of the DWL (Figure 6). For all the 8 days in this example, the formation of a DWL occurs shortly after sunrise. Temperatures rise in the DWL until early afternoon, when they begin to fall, reaching a minimum just before sunrise the next day. Below the surface, the heat energy is trapped within a few meters of the surface until mid afternoon, when the trapped heat begins mixing down into the layers beneath. In the hours before dawn, an approximately uniform layer is created from the surface down to the main thermocline. On 24 June, there was little wind in the afternoon and relatively weak surface heat loss and the heat input into the layer during the day remained trapped near the surface.

[33] An example from the same buoy (PACS North) of 10 days of warming in which the diurnal warming was weaker (about $0.1^{\circ} \mathrm{C}$ ) is shown in Figure 7. A distinct DWL is not visible on all the days shown. For 8 days, a DWL is present and the input heat can be observed penetrating to depths below $40 \mathrm{~m}$ in the afternoon when wind-induced mixing deepens the layer. Overnight, the temperature over the full depth of the layer mixes to a relatively uniform temperature prior to the onset of the next day's solar warming. The surface conditions are approximately constant during this period and cannot account for the subdiurnal temperature variations. There is a slight but steady decrease in wind speeds prior to 6 April, when wind speeds and latent heat flux increase again.

[34] Through both the examples described above, the F96 model does a reasonably good job of capturing the magnitude of the surface warming and the trapping depth (root mean square error, RMSE, of $0.04^{\circ} \mathrm{C}$ ). The W96 model is consistently biased high in the two examples shown (RMSE $\left.0.13^{\circ} \mathrm{C}\right)$.

Table 5. Diurnal Warming F96 Model Predictions for Each Location $^{\mathrm{a}}$

\begin{tabular}{lcccccccc}
\hline Buoy Mooring & \multicolumn{3}{c}{$\begin{array}{c}\text { SST } \\
\text { Days }\end{array}$} & $\begin{array}{c}\text { Depth }(\mathrm{cm}) \\
\text { RMSE }\end{array}$ & $\begin{array}{c}{ }^{\circ} \mathrm{C} \\
\text { SS Fit }\end{array}$ & $\begin{array}{c}\text { Mean } \\
\text { Slope }\end{array}$ & $\begin{array}{c}\text { Max } \\
\Delta S S T\end{array}$ & $\Delta$ SST \\
\hline Arabian Sea & 365 & 17 & 0.95 & 0.13 & 0.84 & 0.39 & 1.91 \\
PACS North & 492 & 25 & 0.96 & 0.11 & 0.83 & 0.30 & 1.65 \\
PACS South & 497 & 5 & 0.93 & 0.16 & 0.98 & 0.39 & 4.17 \\
Stratus & 2576 & $5 / 50$ & 0.95 & 0.11 & 0.74 & 0.22 & 3.71 \\
KAUST & 782 & 65 & 0.89 & 0.35 & 0.37 & 0.25 & 1.02 \\
All moorings & 4712 & & 0.88 & 0.18 & 0.67 & 0.26 & 4.17 \\
\hline
\end{tabular}

${ }^{\mathrm{a}} r$ is the correlation coefficient between the observations and the F96 model predictions of maximum daily near-surface warming. RMSE is the root mean squared difference between the observations and the F96 model predictions of maximum daily near-surface warming. LS fit slope is the slope of the first-order least squares fit through the model predictions relative to the observed maximum daily near-surface warming. $\Delta$ SST is the F96 model's prediction of maximum daily near-surface warming. 


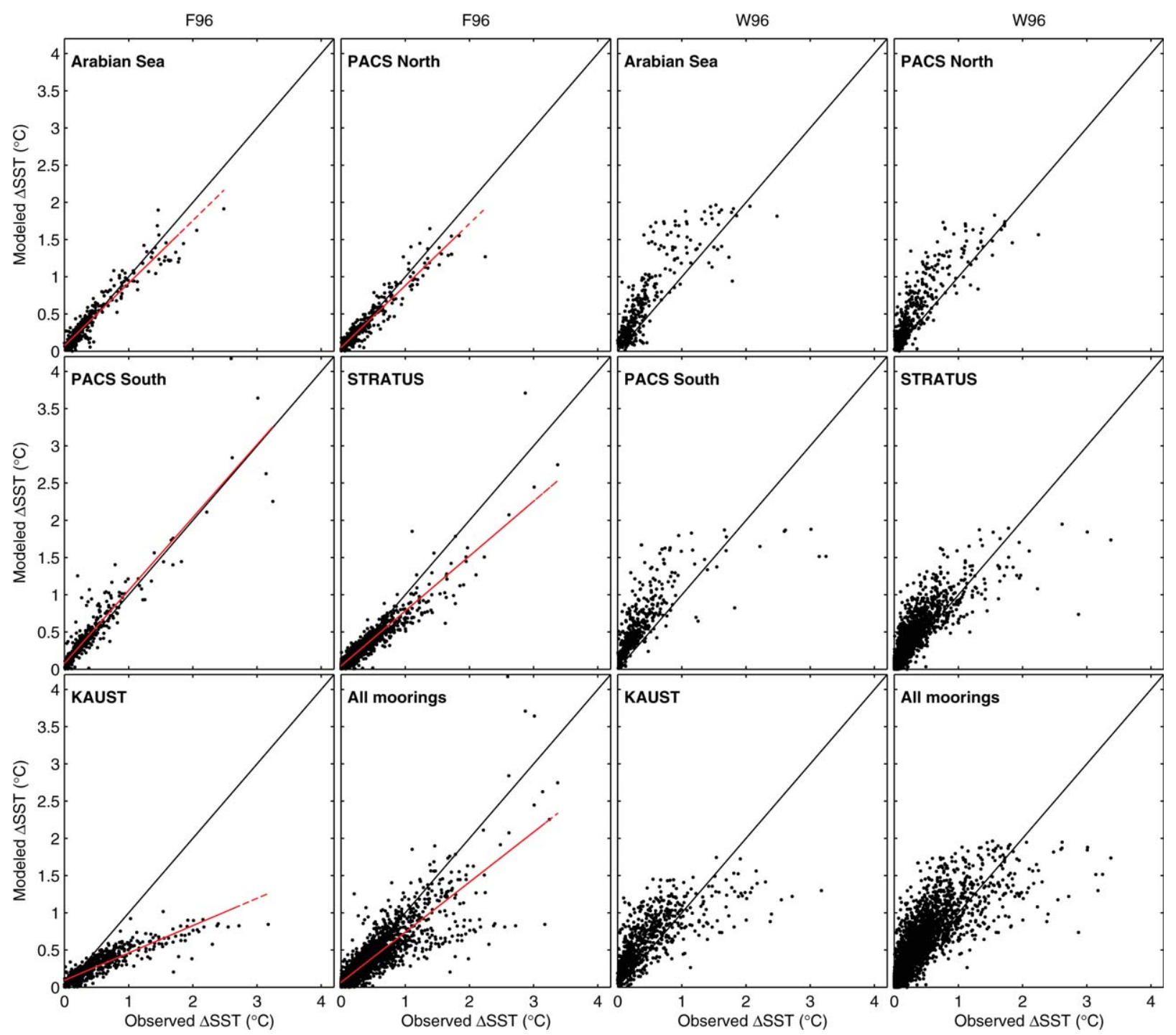

Figure 3. Observation of daily maximum observed $\Delta \mathrm{SST}$ and the corresponding prediction of daily maximum $\Delta$ SST from the F96 and W96 models for five mooring sites. $\Delta$ SST is the difference between the maximum SST during the daytime warming (and prior to the onset of convection as predicted by the F96 model) and the SST just prior to the time that warming begins, as determined by the F96 model. A linear least square fit to the data is shown (red line).

[35] In 8 days of warming observed at the PACS South site $\left(2.7^{\circ} \mathrm{S}, 125^{\circ} \mathrm{W}\right.$; Figure 8$)$, the F96 and W96 models again do a good job of estimating the magnitude of the surface warming. In the morning of 25 January, a brief but heavy rain event occurs. This leads to a cooling at the surface of approximately $0.5^{\circ} \mathrm{C}$ prior to the onset of the day's solar warming.

[36] A clear diurnal cycle is visible penetrating to depths of up to $60 \mathrm{~m}$ in an example of 10 days of measurements from the Arabian Sea mooring $\left(15.5^{\circ} \mathrm{N}, 61.5^{\circ} \mathrm{E}\right.$; Figure 9). The magnitude of the warming in this example is small, less than $0.5^{\circ} \mathrm{C}$ at the surface and approximately $0.1^{\circ} \mathrm{C}$ at $30 \mathrm{~m}$ or deeper. In each of the 10 days, the heat input to the DWL is trapped near the surface till mid afternoon, when the momentum input by the wind overcomes the stable stratification and increases $D_{T}$, entraining the water below and mixing the heat of the DWL into the cooler waters below. As in some of the previous examples, the temperature anomaly from the previous day's warming has been reduced by mixing and nighttime convection, leaving a relatively uniform mixed layer. The evolution of $D_{T}$ and its day-to-day variations are simulated reasonably well by the F96 model. The winds in this example are at their lightest on 25-28 January, when relatively shallow warm-layer depths $(10-20 \mathrm{~m})$ and large diurnal temperature signals $\left(>0.2^{\circ} \mathrm{C}\right)$ are observed (Figure 9).

[37] The F96 model predictions of surface diurnal warming are biased low relative to the observations at the KAUST mooring $\left(22.17^{\circ} \mathrm{N}, 38.5^{\circ} \mathrm{E}\right)$. This is evident in the 8 days of surface and subsurface temperature at the site shown in Figure 10 (surface warming RMSE of $0.53^{\circ} \mathrm{C}$ ), particularly for the 4 days with the largest diurnal warming (4-6 and 9 August). Surface fluxes show winds generally increasing in the afternoon, after the time of peak warming. 

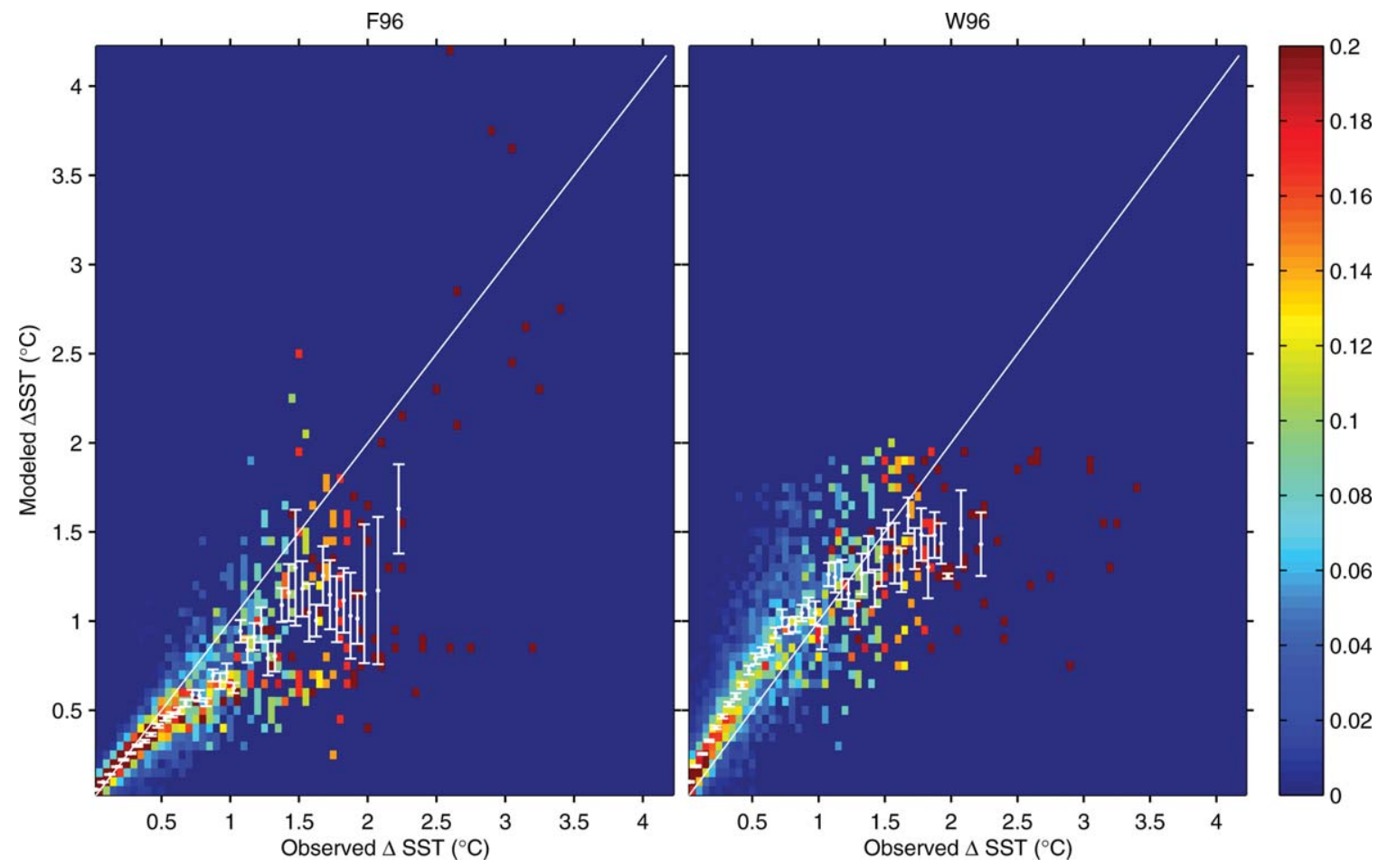

Figure 4. The probability density of an observation of daily maximum observed $\Delta$ SST and the corresponding prediction of daily maximum $\Delta$ SST from the F96 and W96 models. Observed warming is defined as the difference between the minimum predawn SST and the maximum daytime SST. The probability density, shown as color variation, is normalized to the number of values within each observed $\Delta \mathrm{SST}$ bin. Error bars show the standard error of the mean for each $0.05^{\circ} \mathrm{C}$ observed temperature bin.

For the days shown the W96 predictions shows no persistent direction of bias but are scattered (RMSE of $0.43^{\circ} \mathrm{C}$ ). Also shown are $0.65 \mathrm{~m} \mathrm{SST}$ results from the 1-D numerical model [Price et al., 1986]. These results are discussed further in section 5 .

\subsection{Subsurface Velocity}

[38] At the Stratus mooring $\left(20^{\circ} \mathrm{S}, 85^{\circ} \mathrm{W}\right)$ for 375 days from September 2006, high-resolution (1 m bins) ADCP water velocity measurements were made at depths of 5-15 $\mathrm{m}$, and another ADCP sampled the deeper part of the water column with $10 \mathrm{~m}$ wide bins. For this period, the maximum daily (linear) DWL velocity gradient predicted by the F96 model was compared with the simultaneous observed ve-

Table 6. Diurnal Warming W96 Model Predictions for Each Location $^{\mathrm{a}}$

\begin{tabular}{lcccccc}
\hline Buoy Mooring & Days & $\begin{array}{c}\text { SST } \\
\text { Depth }(\mathrm{cm})\end{array}$ & $\mathrm{r}$ & $\begin{array}{c}\text { RMSE } \\
{ }^{\circ} \mathrm{C}\end{array}$ & $\begin{array}{c}\text { Mean } \\
\Delta S S T\end{array}$ & $\begin{array}{c}\text { Max } \\
\Delta S S T\end{array}$ \\
\hline Arabian Sea & 365 & 17 & 0.86 & 0.32 & 0.57 & 1.96 \\
PACS North & 492 & 25 & 0.87 & 0.27 & 0.47 & 1.83 \\
PACS South & 497 & 5 & 0.76 & 0.34 & 0.53 & 1.88 \\
Stratus & 2576 & $5 / 50$ & 0.83 & 0.20 & 0.34 & 1.95 \\
KAUST & 782 & 65 & 0.74 & 0.34 & 0.57 & 1.74 \\
All moorings & 4712 & & 0.81 & 0.26 & 0.43 & 1.96
\end{tabular}

${ }^{\mathrm{a}} r$ is the correlation coefficient between the observations of maximum daily near-surface warming and the W96 model predictions. RMSE is the root mean squared difference between the observations and the W96 model predictions. $\Delta$ SST is the W96 model's prediction of surface warming. locity shear depth averaged over the DWL (using the estimate of $D_{T}$ obtained from the F96 model; Figure 11). The observations necessary to perform this comparison were available on 346 days. There is significant variation in the near-surface currents and a relatively high level of noise in the ADCP measurements. Both vertical and temporal smoothing (averaging over three depth bins and three hourly time steps) was applied to the observed velocities. Periods when the model trapping depth was less than $8 \mathrm{~m}$ or greater than $100 \mathrm{~m}$ were excluded from the comparison.

[39] To our knowledge, this is the first attempt to compare velocity predictions from the F96 model to observations and one of the first to examine velocity within the diurnal warm layer (a brief examination is given in Price et al. [1986]). The modeled shears have a reasonably good correlation with the observations ( $r$ of 0.77 , RMSE of $0.35 \cdot 10^{-2} \cdot \mathrm{s}^{-1}$ ) but are biased low (linear least squares slope is 0.69 , see discussion in section 5.4).

\section{Discussion}

[40] The competing effects of stably stratifying solar insolation and wind-induced mixing both affect the magnitude of the diurnal warming, and these factors are interdependent (Figure 12). This is the qualitative dependence shown in previous observations [e.g., Stommel and Woodcock, 1951; Price et al., 1987], numerical models [e.g., Price et al., 1986] and statistical models (e.g., W96). In addition to measurement uncertainty (section 2), the variability in our observations can be partly explained by the 


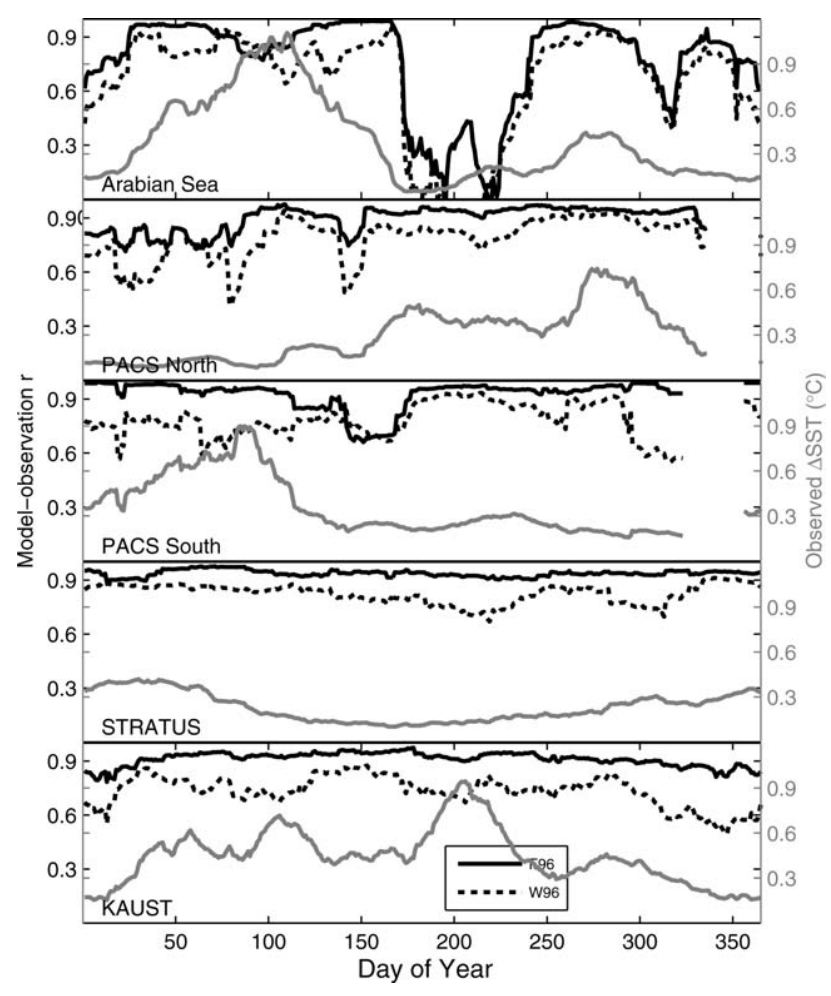

Figure 5. Seasonal, site-by-site variation in the correlation between the observations and model predictions of maximum daily near-surface warming for the F96 model (solid black lines) and the W96 model (dashed black lines). The $r$ and maximum daily observed $\Delta$ SST (solid gray lines) calculated using a 30 day wide moving window. If less than 30 measurements were included in the window then that point is not plotted. Values of $r$ exceeding 0.45 are statistically different than zero at $99 \%$ confidence.

numerous other physical factors. The simplicity of the F96 model is used here to explore these factors and provide qualitative insight into the behavior of the DWL.

\subsection{Convection}

[41] A daytime convective sublayer is frequently present in high vertical resolution observations of the DWL; this phenomenon is illustrated here by a single day's observations at the PACS North mooring (Figure 13). Following the time of maximum surface temperature at approximately 14:00 local time the upper ocean begins to cool, beginning with the measurement at $5 \mathrm{~cm}$ depth obtained from a floating sensor, even though the net surface heat flux is still positive. As the solar radiation and net surface heat flux begin to reduce, the temperature gradient in the upper 1-2 m weakens, presumably because the sensible, latent and longwave heat loss from the sea surface exceed the heat gain from absorption of solar radiation near the surface, causing a shallow convectively mixed layer near the ocean surface. As the heating reduces further, the convection deepens, weakening or destroying the stable stratification present due to diurnal warming. The process begins near the surface and deepens as the cooling continues until a time close to $19: 00$ local when the upper $2.5 \mathrm{~m}$ are nearly of a uniform temperature. For the temperature measurement depths below $1 \mathrm{~m}$ in the example, it is notable that the maximum temperature is reached as the stratification disappears. At night the floating sensor is noticeably cooler than the waters beneath it $\left(0.27^{\circ} \mathrm{C}\right.$ cooler than the $2 \mathrm{~m}$ measurement), as would be expected in the presence of nighttime convection. Although the floating sensors are susceptible to physical damage and biological fouling on long deployments, this example is from a time early in the deployment, and we have no reason to believe that the measurements shown are in error.

[42] The F96 model assumes a linear temperature profile and that deepening of the warm layer is associated with shear instabilities represented in the model by the Richardson number criterion. The presence of a convective sublayer in the late afternoon may be expected to lead to an overestimation of the near-surface warming by the F96

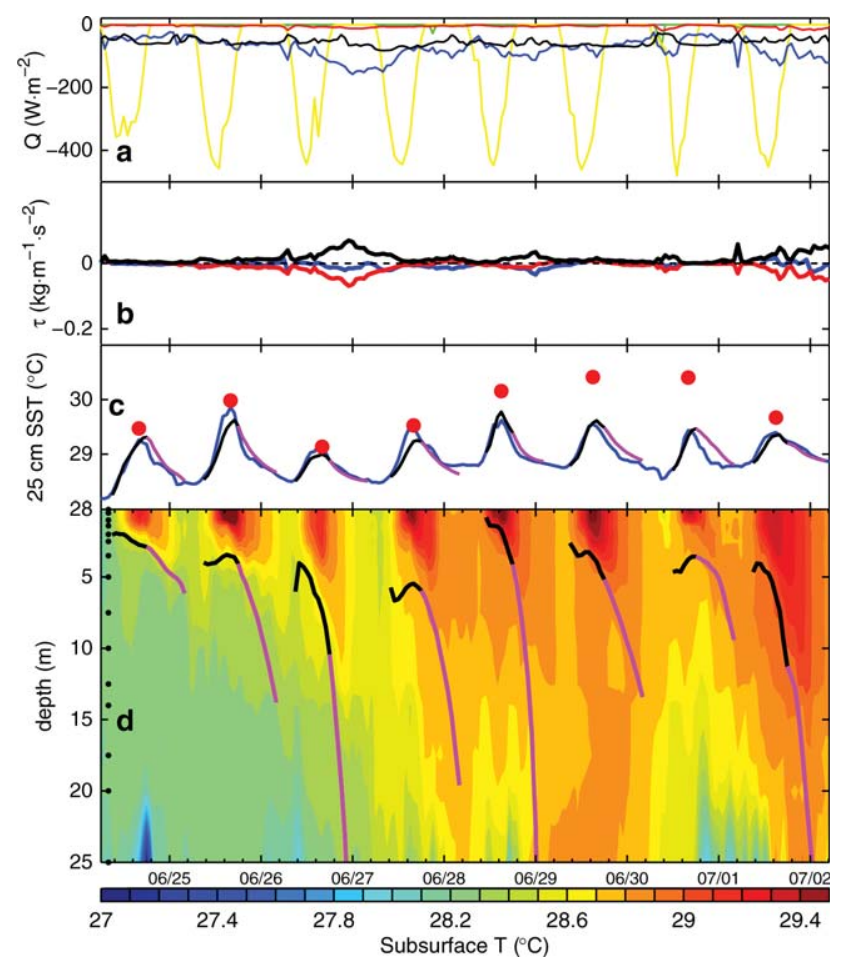

Figure 6. Eight days of surface fluxes, SST, and subsurface temperature measurements - PACS North buoy mooring, June 1997. (a) Surface heat fluxes (positive into the ocean); Solar shortwave radiation, with sign reversed and magnitude halved for clarity of presentation $\left(S_{w}\right.$; yellow line); Latent heat flux ( $Q H$; blue line); Sensible heat flux $(Q B$; red line); Long-wave radiation surface flux $(Q l$; black line); Rain heat flux ( $Q r$; green line). (b) Surface wind stress decomposed into eastward component (blue line), northward component (red line), and magnitude (black line). Wind stress calculated via TOGA-COARE bulk flux algorithms. (c) Observed SST (25 cm depth; blue line) and modeled surface temperatures. F96 model shown as black/magenta lines, with the color change indicating our estimate of onset of convection (section 5.1). W96 peak daily SST prediction shown as red dots. (d) Subsurface temperature as a function of time and depth. Predictions of $D_{T}$, from the F96 model are indicated by black/magenta lines. Black dots indicate temperature measurement depths. 




Figure 7. As per Figure 6 for 10 days of surface fluxes, SST $(25 \mathrm{~cm})$, and subsurface temperature measurementsPACS North mooring, April 1998. Note that the total range of subsurface temperatures contoured is only about $0.5^{\circ} \mathrm{C}$.

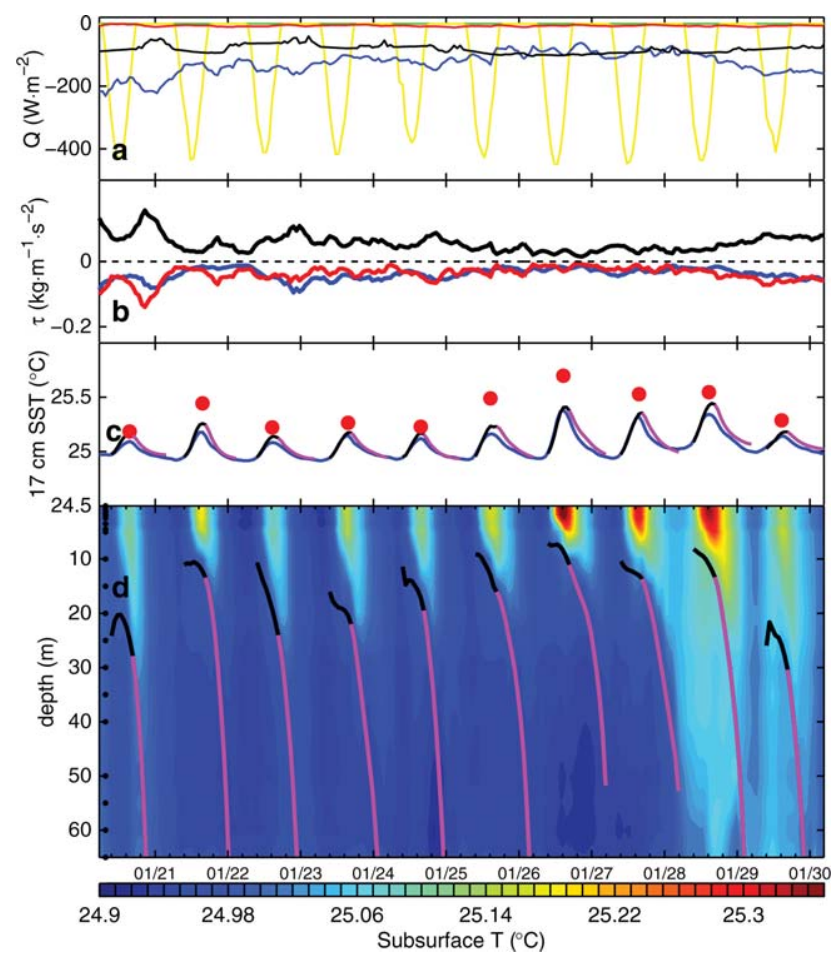

Figure 9. As per Figure 6 for 10 days of surface fluxes, SST $(17 \mathrm{~cm})$, and subsurface temperature measurements Arabian Sea mooring, January 1995.

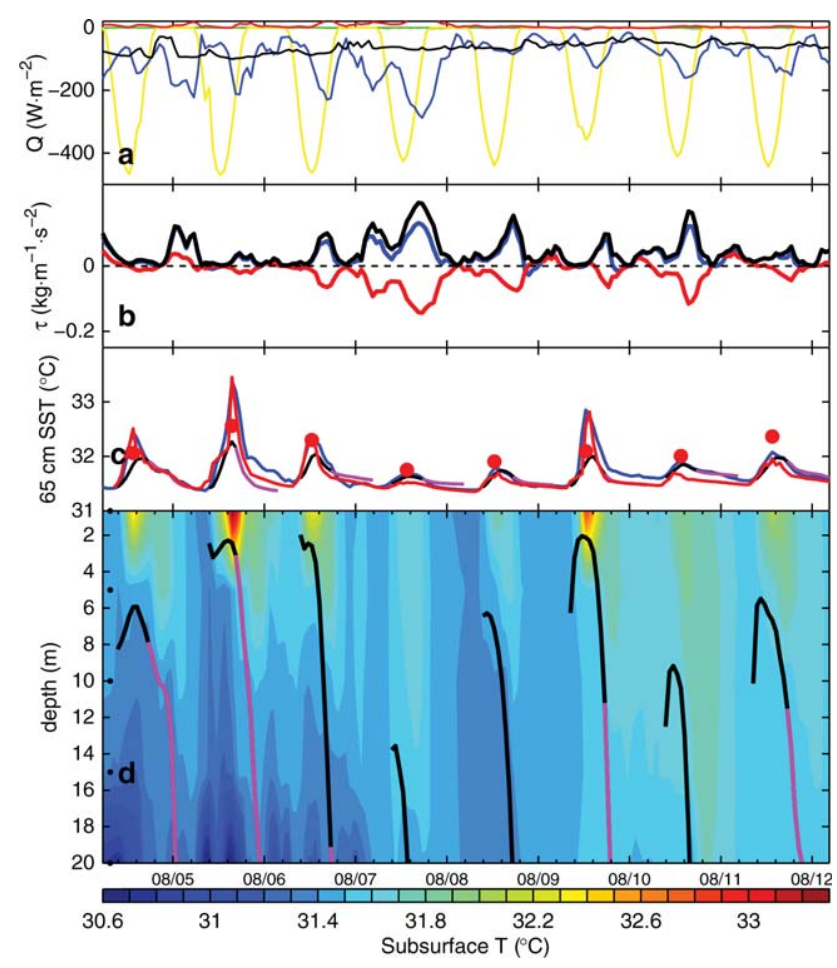

Figure 10. As per Figure 6 for 8 days of surface fluxes, SST $(65 \mathrm{~cm})$, and subsurface temperature measurementsKAUST mooring, August 2010. Also shown are $65 \mathrm{~cm}$ SST predictions from a 1-D numerical model [Price et al., 1986] (red line, Figure c).
Figure 8. As per Figure 6 for 8 days of surface fluxes, SST $(5 \mathrm{~cm})$, and subsurface temperature measurementsPACS South mooring, January 1998. 

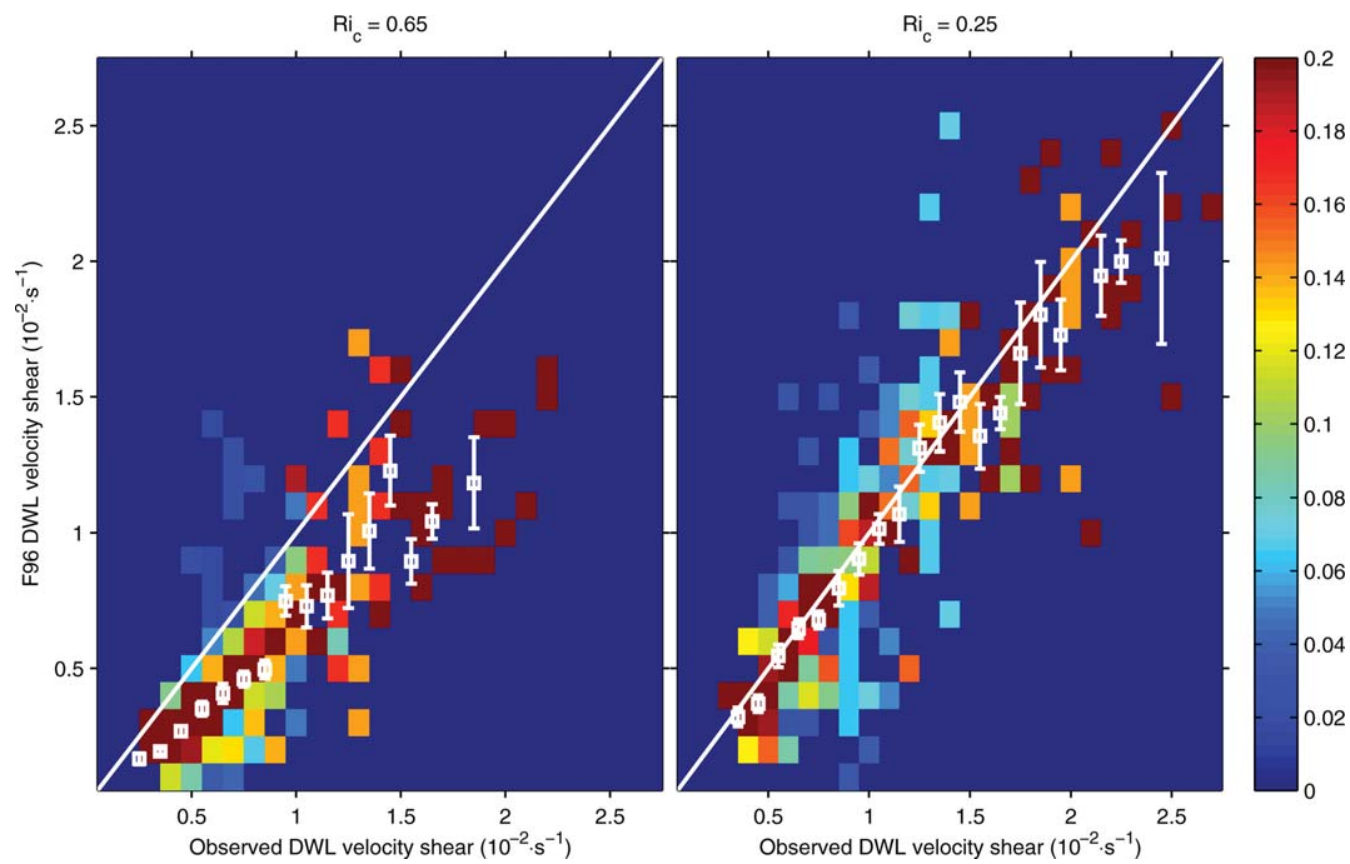

Figure 11. Comparison of daily maximum F96 model predictions of velocity shear within the DWL and observations (ADCP) over 346 days at the Stratus site. The F96 model is run using a $R i_{c}$ criterion of either (left plot) 0.65 or (right plot) 0.25 . ADCP measurements are in $1 \mathrm{~m}$ depth bins at depths from 5 to $15 \mathrm{~m}$, and $10 \mathrm{~m}$ depth bins at greater depths. Only measurements made within the F96 prediction of $D_{T}$, when $D_{T}$ was in the range $8-100 \mathrm{~m}$, are included. The probability density, shown as color variation, is normalized to the number of values within each observed velocity shear bin. Error bars show standard error of the mean for each observed shear bin. Bin sizes $0.1 \times 10^{-2} \cdot \mathrm{s}^{-1} \times 0.1 \times 10^{-2} \cdot \mathrm{s}^{-1}$.

model, both because of the nonuniformity of the temperature gradient (e.g., Figure 7) and because the convection may promote vertical mixing between the DWL and the cooler waters below, beyond what might be expected from the bulk shear and stratification. This may be part of the reason that the observed SST cooling late in the afternoon after the peak of diurnal warming is often more rapid than in the F96 model (e.g., Figures 7 and 6).

[43] An approximation of the time when the convective sublayer begins to deepen can be obtained from the time when the surface cooling becomes larger than the heating applied to the DWL (i.e., when $\delta S_{w}-Q<0$ ). This is the heating applied to a much larger layer than that in which convection is initially occurring, and shallow upper ocean convection is likely occurring before the time when the DWL begins to experience a net cooling. However this method appears to give a reasonable approximation of the time the convective sublayer begins deepening noticeably (e.g., Figure 13d). In the case studies shown here, the estimated time of convective sublayer deepening has been indicated by the transition from a black to a magenta line.

\subsection{Solar Absorption}

[44] The solar radiation absorption model used in the original development of the F96 model was a three-band form of the Soloviev [1982] model deemed appropriate for the conditions in which the model data were obtained (tropical western Pacific, water described as 'moderately clean'). Absorption profiles are likely to vary between sites (and at different times at a particular site) and parameterization of the absorption profile in terms of surface chloro- phyll concentration [i.e., Ohlmann, 2003] represents one of the best available approaches.

[45] The majority of solar insolation is absorbed within the upper few meters of the ocean. However, some solar radiation will reach a significant depth $(10 \%$ of solar radiation penetrating deeper than $50 \mathrm{~m}$ and $5 \%$ penetrating deeper than $100 \mathrm{~m}$ with the F96 three-band absorption profile). Energy that penetrates to a depth deeper than $D_{T}$ is lost to the F96 model and will not be accounted for if $D_{T}$ deepens later in the day. The effect is usually small unless $D_{T}$ is very shallow, i.e., in light winds. Assuming an invariant $D_{T}$ of $5 \mathrm{~m}$ and insolation of $500 \mathrm{~W} \cdot \mathrm{m}^{-2}$ (appropriate for clear sky conditions, e.g., Price et al. [1986]), the meter deep layer of water beneath the trapping depth will warm by approximately $0.1^{\circ} \mathrm{C}$ over $12 \mathrm{~h}$. In a full numerical model of the upper ocean [e.g., Price et al., 1986] which may include 1000 or more depth levels, the input solar energy can be fully accounted for. We do not see how this would be possible in a simple one-level model such as F96, so it seems that conservation requirements must be relaxed.

\subsection{Statistical Model Performance}

[46] The statistical W96 model is intended to predict the diurnal cycle of skin temperature and hence the finite depth buoy measurements $(5-65 \mathrm{~cm})$ may be expected to have a slightly smaller diurnal cycle. As the DWL is typically at a depth of a few meters to 10 s of meters, the error associated with the $O(0.5 \mathrm{~m})$ measurement depth is expected to be small except during days of very large diurnal warming and shallow warm-layer depths. The W96 model does not perform better at buoy locations with shallower SST 

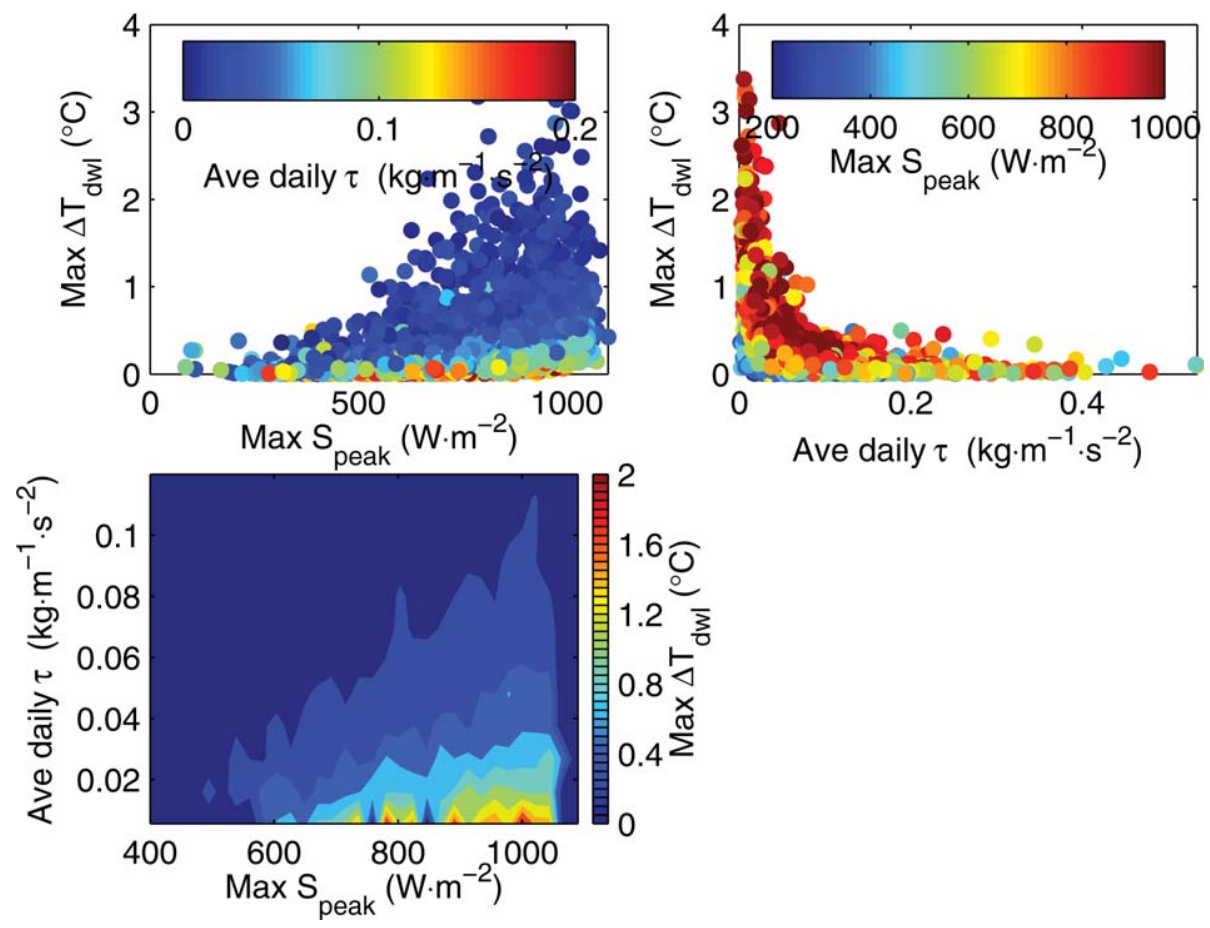

Figure 12. Each plot provides a different presentation of the same data to illustrate the observed relation between maximum daily daytime surface warming (Max $\Delta T_{d w l}$ ), daily peak solar insolation (Max $S_{\text {peak }}$ ), and mean daily wind stress (Ave daily $\tau$ ). (top left) Maximum daily daytime surface warming dependence on daily peak solar insolation, mean daily wind stress shown as color variation. (top right) Maximum daily daytime surface warming dependence on mean daily wind stress, daily peak solar insolation shown as color variation. (bottom) Maximum daily daytime surface warming dependence on daily peak solar insolation and mean daily wind stress.

measurement depths. It is important to note that the disagreement at large values of the observed diurnal warming cannot be a result of the finite depth of the measurements because the measurements being too deep would tend to reduce the observed warming.

[47] The statistical model does not account for any variation in solar absorption or wind vector over the course of the day. The limited range of forcings in the model output used to develop the W96 regression model (SST above $2^{\circ} \mathrm{C}$ for extremely light winds and maximum value of $2.9^{\circ} \mathrm{C}$, minimum average daily wind speed $0.7 \mathrm{~m} \cdot \mathrm{s}^{-1}$ ) and the logarithmic nature of the model dependence on heating and wind stress may rule out higher values of predicted warming.

\subsection{Physical Model Performance/Model Tuning}

[48] The performance of the F96 model (and to a lesser extent, the Price et al. [1986] model) can be modified with the "tuneable" critical Richardson number criterion (section 3). A value of 0.65 (as used in F96 and Price et al. [1986]) gave good agreement at the PACS North, PACS South and Arabian Sea moorings. At the Stratus mooring the F96 predictions of both temperature and velocity DWL anomaly are biased low using $R i_{c}=0.65$ (linear least squares slope of model to observation of 0.74 and 0.69 , respectively; Table 5 and Figure 11). The low bias is reduced if a lower critical value is used $\left(R i_{c}=0.25\right.$ results in temperature and velocity linear least squares slopes of 0.96 , with $r$ of 0.93 and 0.81 , respectively; Figure 11).
[49] Better model agreement obtained in this way can be attributed either to the changing $R i_{c}$ compensating for another parameter that is systematically wrong at a particular site (the likeliest being solar absorption, section 5.2) or perhaps to the changing $R i_{c}$ compensating for a physical effect missing from the model which is of importance in some locations and not others. The model to observation agreement using $R i_{c}=0.25$ instead of 0.65 also improved at the PACS North mooring (slope 0.96), was worsened at the PACS South (slope 1.29) and Arabian Sea (slope 1.22) moorings, and was only slightly changed at the KAUST mooring (slope 0.39).

[50] In addition to the choice of Richardson number, the F96 model neglects several physical factors which may explain the variation of model performance between the different sites. A recent study [Gentemann et al., 2009, hereafter G09] tested the F96 model against 72 days of DWL observation, obtained from upper ocean profiler deployments from a cruise ship in the Caribbean sea and during four research cruises (observations described in Gentemann and Minnett [2008]). G09 determined a number of modifications to the F96 model which improved the model agreement with those observations. The most significant of these are: replacing the three-band solar absorption with a nine-band model [Paulson and Simpson, 1981], additionally modified with an empirically determined $20 \%$ increase to absorption; adding empirically determined decay terms to the heat and momentum trapped within the DWL to account for exchange across the base of the DWL; 


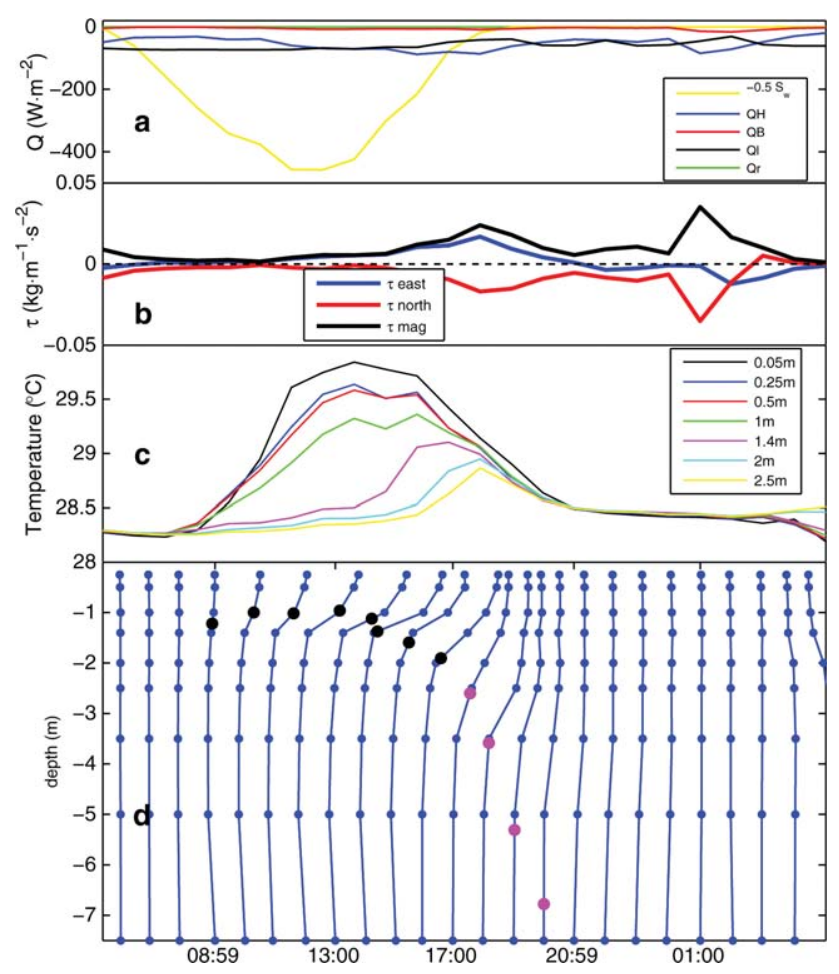

Figure 13. One day's (21 June 1997) temperature measurements from the PACS North buoy mooring. (a) Surface heat fluxes (positive into the ocean); Solar shortwave radiation, with sign reversed and magnitude halved for clarity of presentation $\left(S_{w}\right.$; yellow line); Latent heat flux $(Q H$; blue line); Sensible heat flux $(Q B$; red line); Longwave radiation surface flux ( $Q l$; black line); Rain heat flux ( $Q r$; green line). (b) Surface wind stress decomposed into eastward component (blue line), northward component (red line), and magnitude (black line). Wind stress calculated via TOGA-COARE bulk flux algorithms. (c) Temperature from the upper seven temperature sensors at $1 \mathrm{~h}$ intervals. (d) Subsurface temperature, shown at hourly intervals and scaled so that $1 \mathrm{~h}$ equals $0.5^{\circ} \mathrm{C}$, with the measurement time corresponding to the horizontal position of the profile at 7.5 $\mathrm{m}$ depth. The F96 model's predictions of $D_{T}$ are indicated by black/magenta dots, with the color change indicating our estimate of the onset of convection (section 5.1).

and replacing the linear profile of temperature within the warm layer assumed by the F96 model with an exponential profile, dependent on wind speed, and normalized by the F96 prediction of DWL heat content.

[51] A comparison of the G09 model with the observations reported here found no improvement over that of the F96 model (overall $r$ of 0.81 , RMSE of $0.32^{\circ} \mathrm{C}$ and least squares slope of 1.20). The G09 model also performs worse than the F96 model if a chlorophyll-dependent solar absorption model is used (overall $r$ of 0.82 , RMSE of $0.23^{\circ} \mathrm{C}$ and least squares slope of 0.62 ). It is noted that deviations from a linear temperature profile within the DWL will be dependent on the details of the forcing and response at the location in question, e.g., the presence of a convective sublayer. Observed daytime temperature gradients clearly vary with time but are reasonably approximated by linear profiles prior to the time when convection begins to exert a more substantial influence on upper ocean structure (e.g., Figure 14). The empirical nature of the modifications proposed by G09 may make them appropriate only for conditions similar to those in which they were determined.

\subsection{Variable Winds}

[52] During the period when a DWL is present in the F96 model, wind stress magnitude is integrated and used in determining the depth of the warm layer and hence the magnitude of the temperature and velocity gradients. Shifts in wind direction could reduce the momentum in the upper ocean if the wind stress acts to oppose momentum that it had put into the surface currents earlier. A diurnal warming effect is detectable in large parts of the midlatitudes [Stuart-Menteth et al., 2003] and at these latitudes changes in current direction due to the earth's rotation could act to reverse the direction of momentum input into the DWL. In steady wind conditions, this rotation could reduce the accumulated momentum within the DWL, an effect observed by Price et al. [1986]. There are occasional examples in the data reported here when shifts in wind direction appear to lead to an underestimation of the F96 model prediction of DWL magnitude. By following the approach of F96, it is straightforward to modify the one layer model with vector wind stress and a Coriolis term and hence include rotational effects. An example of the SST prediction from this model is shown for 1 day's measurements at the KAUST mooring (Figure 15). The change in wind direction occurring in the late morning leads to surface warming larger $\left(0.47^{\circ} \mathrm{C}\right)$ than that predicted by the F96 model. Use of a 2-D momentum equation reduces the error to $0.15^{\circ} \mathrm{C}$. However, in the observations reported here, significant shifts in wind

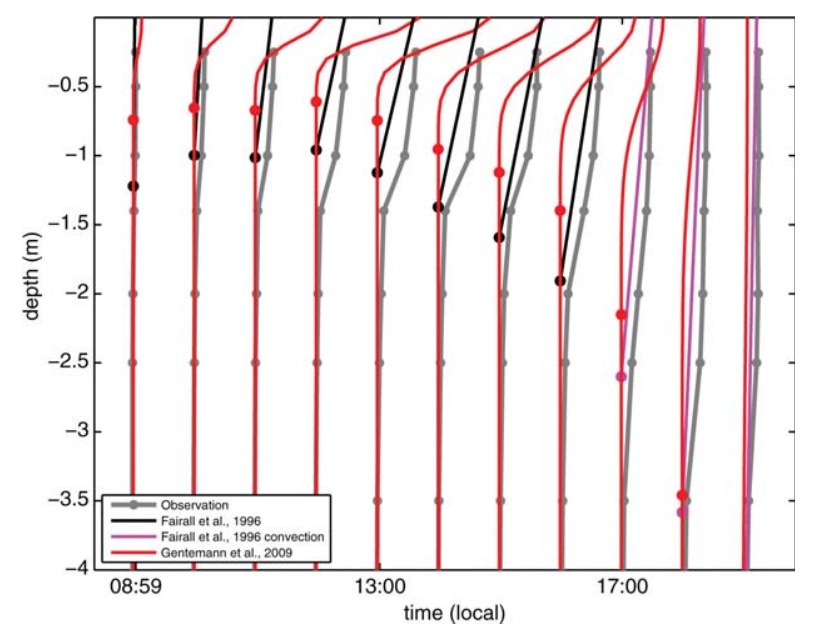

Figure 14. One day's (21 June 1997) subsurface temperature measurements from the PACS North buoy mooring. Subsurface temperature (gray line, circles indicate measurement depth), shown at hourly intervals and scaled so that $1 \mathrm{~h}$ equals $2^{\circ} \mathrm{C}$, with the horizontal position of the temperature profile at $7.5 \mathrm{~m}$ depth corresponding to the measurement time. The F96 (black/magenta lines, with the color change indicating our estimate of the time of onset of convection; section 5.1) and G09 (red) model's prediction of the DWL temperature profile are shown as well as the model estimates of $D_{T}$ (circles). 


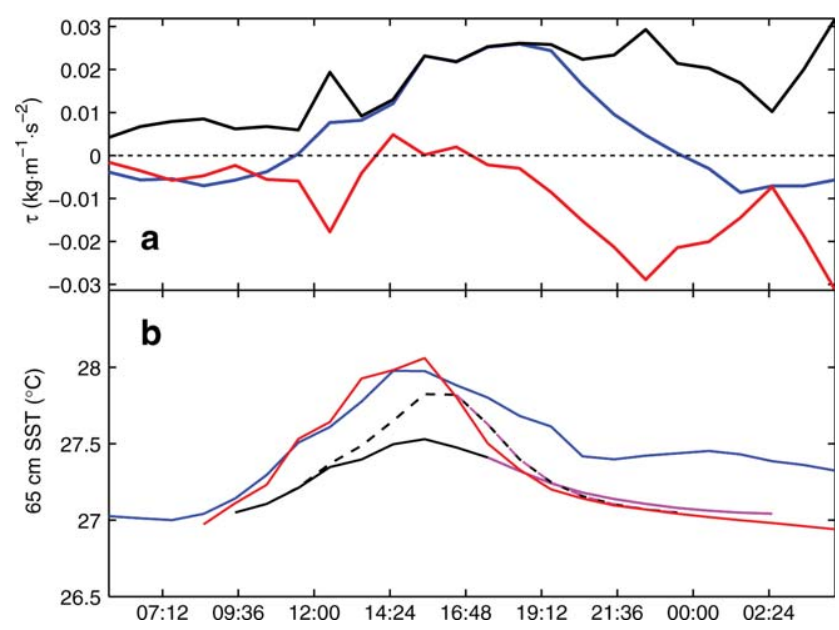

Figure 15. Surface wind stress and surface warming at the KAUST mooring (19 February 2010). (a) Surface wind stress decomposed into eastward component (blue line), northward component (red line), and magnitude (black line). (b) Observed SST (65 cm depth; blue line) and modeled surface temperatures. Also shown are $65 \mathrm{~cm} \mathrm{SST} \mathrm{esti-}$ mates from: F96 (black/magenta lines); a version of F96 with additional vector wind stress and Coriolis terms (dashed black/magenta lines); and the 1-D numerical Price et al. [1986] model (red line).

direction before the time of peak warming were infrequent. As such this addition did not significantly improve the overall agreement with observation of the model's prediction of DWL warming or velocity.

\subsection{Poor Model Performance at KAUST}

[53] Whilst the KAUST site was relatively close to land, and is known to have been affected by dust deposition on the solar radiation sensors potentially causing underestimation of the solar insolation, this does not appear to be the cause of the model underestimation. Simulation of the upper ocean dynamics at the KAUST site using a 1-D dynamical model [Price et al., 1986] utilizing the same solar absorption parameters as used here in the F96 model [Ohlmann, 2003], obtained closer agreement with observation ( $r$ of 0.9 , RMSE, of $0.24^{\circ} \mathrm{C}$, linear least squares slope 0.92 ) as shown in the $65 \mathrm{~cm}$ SST prediction in Figures 10c and 15. The particular conditions at the KAUST site (e.g., the strong land-sea breeze) may not be well represented by a one-layer model, with its necessary simplifications of energy conservation, time dependence and vertical structure, leading to the poor performance of F96 here.

\subsection{Freshwater Forcing}

[54] Both precipitation and evaporation will modify the salinity and hence the density of surface water, increasing or decreasing the stratification of a DWL. Large precipitation events are generally associated with heavy cloud coverage and strong winds and as such would not normally be of significance to DWL dynamics. However, in certain situations, such as heavy rain early in the morning followed by calm sunny conditions, precipitation may have a significant impact on the DWL, e.g., as on 25 January 1998 in Figure 8. If measurements of evaporation and precipitation are available then it is straightforward to include the effects surface freshwater fluxes on the stratification of the warm layer in the F96 model via an additional term, derived from the one-dimensional salinity equation. However, the addition of this term did not make a significant difference to the agreement of the model with observation (less than $1 \%$ difference to results at each site).

\subsection{Advection}

[55] Horizontal advection of water of differing properties has been previously observed to play an important role in the dynamics of warm-layer formation and restratification [e.g., Brainerd and Gregg, 1993]. Several examples of this are apparent in the observations reported here. At the Arabian Sea Mooring during the regional monsoon period from June to September, the lack of balance between the heat input and the integrated warming of the near-surface ocean (upper $62 \mathrm{~m}$; Figure 16a) suggests that advective processes have occurred, leading to the poor model performance (Figure 5).

[56] The temperature decrease in the upper ocean over 4-8 April at the PACS North buoy (Figure 7) begins before the increase in wind stress and latent heat loss and may be due to horizontal advection of slightly cooler water. At the same buoy on 26 and 27 June (Figure 6), strong winds lead to a small surface diurnal warming of approximately $0.5^{\circ} \mathrm{C}$ and a marked deepening of the warm layer to greater than $10 \mathrm{~m}$ in the afternoon of both days, mixing and distributing the heat from the DWL into the cooler, deeper water. Following the input of heat on these 2 days, the upper ocean remains at a warmer temperature (approximately $1^{\circ} \mathrm{C}$ ) for the remainder of the period, with the subsequent diurnal warming occurring in addition to this prior warming. The integrated warming of the near-surface ocean (upper $20 \mathrm{~m}$ ) approximately balances the surface heat flux during the first 4 days shown (Figure 16b). On 30 June the balance

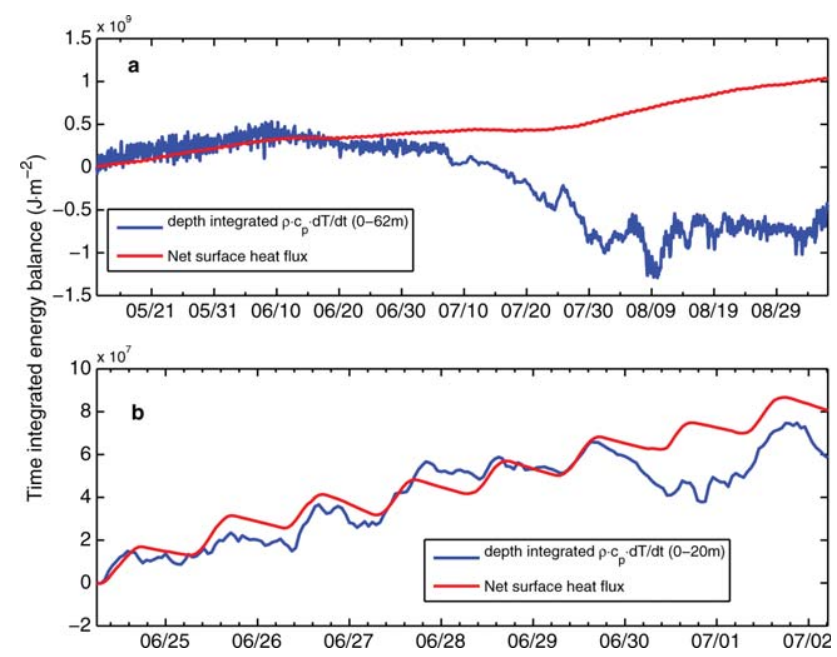

Figure 16. Integral with time of the vertically integrated heating of the upper ocean (blue line) and net surface heat flux (red line; positive into the ocean) at: (a) the PACS North buoy mooring for the period shown in Figure 6, heating integrated over the upper $20 \mathrm{~m}$. (b) The Arabian Sea mooring prior to and during the regional monsoon in 1995 , heating integrated over the upper $60 \mathrm{~m}$. 


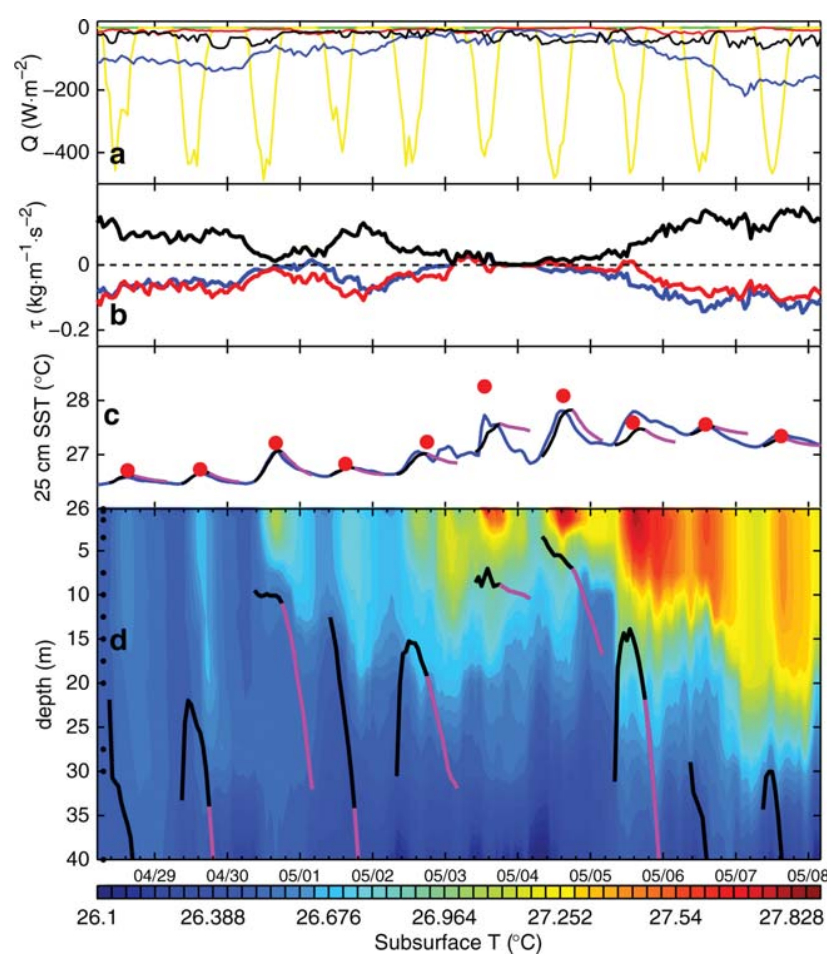

Figure 17. As per Figure 6 for 10 days of surface fluxes, SST $(25 \mathrm{~cm})$, and subsurface temperature measurementsPACS North mooring, May 1998.

between the surface energy flux and upper ocean warming is lost, suggesting that an episode of advection has occurred.

\subsection{Pre-Existing Stratification}

[57] The F96 model assumes that any stratification created by the previous day's insolation is removed overnight and the warming begins each day on a well-mixed upper ocean layer. In a full numerical upper ocean model [e.g., Price et al., 1986; Large et al., 1994] pre-existing stratification can be accounted for in a straightforward way. The assumption of an initially well-mixed upper ocean is often reasonable (Figures 6, 7, and 9). However, stratification of the upper ocean resulting from mean warming of the surface, precipitation, advection of warm surface water and other effects can prevent the warm layer from deepening, leading to greater than predicted surface warming (e.g., Figure 17, 5-8 May).

\subsection{Detrainment}

[58] When the F96 model DWL shallows (i.e., during detrainment), the heat and momentum within the layer is retained in the new, shallower layer, an unrealistic assumption. Detrainment is a common effect at the mooring sites examined here, occurring on approximately $71 \%$ of the days examined, with a mean daily detrainment depth of $3.52 \mathrm{~m}$. Detrainment tends to occur in the morning as solar radiation intensifies, but before the layer has warmed significantly, hence the effect on the model is likely to be small as the amount of integrated heat and momentum within the layer in the initial hours will be relatively minor. Examples of this early morning detrainment can be seen in the $D_{T}$ predictions in Figures 6-9.

\section{Conclusions}

[59] The 4712 days of high-quality surface and subsurface observations from five different mooring sites reported in this study illustrate the regional (Figure 3) and seasonal (Figure 5) variations in the magnitude and dynamics of the DWL under a variety of forcing conditions. The variability of the forcing and the response of the upper ocean to the forcing present a significant challenge in accurately modeling the behavior of the DWL. This challenge is especially severe for statistical models, or those incorporating empirically derived components, developed and calibrated using necessarily limited ranges of conditions.

[60] The performance of the one-layer F96 model examined in this study was found to vary appreciably between the different mooring sites, both overestimating (PACS North and South sites in the eastern tropical Pacific) and underestimating (KAUST site in Red Sea and Stratus site in eastern subtropical Pacific) the mean surface warming response. The simplicity of the F96 model allows qualitative insight into the dynamics of the DWL and its dependence on solar absorption, convection, advection, detrainment. There is the potential to straightforwardly include additional physics (vector winds and freshwater terms) in the one-layer model. However, full 1-D upper ocean models, such as those of Price et al. [1986], Large et al. [1994], and Kantha and Clayson [1994] require the same inputs as F96, and are preferable if accurate estimation of upper ocean warming is required.

[61] Acknowledgments. We thank the members of the WHOI Upper Ocean Processes Group and the ships crews who deployed the surface moorings and recovered the data described in this paper. J.P. was supported for part of this work by a graduate exchange studentship from the Graduate School of the National Oceanography Centre, Southampton. J.T.F. was supported by NSF OCE Award 0745508 , the Charles D. Hollister Fund for Assistant Scientist Support, and the John E. and Anne W. Sawyer Endowed Fund in Special Support of Scientific Staff. R.A.W. was supported by the Office of Naval Research for the deployment of the Arabian Sea surface mooring, and by the NOAA Climate Program and Climate Observation Division for the deployment of the PACS and Stratus surface moorings. J.T.F. was supported under a cooperative program between WHOI and King Abdullah University of Science and Technology (KAUST; Awards USA00001, USA00002, and KSA00011) of the Kingdom of Saudi Arabia for the deployment of the KAUST surface moorings.

\section{References}

Anderson, S. P., A. Hinton, and R. A. Weller (1998), Moored observations of precipitation temperature, J. Atmos. Oceanic Tech., 15(4), 979-986.

Anderson, S. P., K. Huang, N. J. Brink, M. F. Baumgartner, and R. A. Weller (2000), Pan American Climate Study data report, Tech. Rep. WHOI-2000-03, 153 pp., Woods Hole Oceanogr. Inst., Woods Hole, Mass.

Brainerd, K. E., and M. C. Gregg (1993), Diurnal restratification and turbulence in the oceanic surface mixed layer: 1. Observations, J. Geophys. Res., 98(C12), 22,645-22,656.

Bretherton, C. S., T. Uttal, C. W. Fairall, S. E. Yuter, R. A. Weller, D. Baumgardner, K. Comstock, R. Wood, and G. B. Raga (2004), The EPIC 2001 stratocumulus study, Bull. Am. Meteorol. Soc., 85(7), 967-977, doi:10.1175/BAMS-85-7-967.

Castro, S. L., G. A. Wick, and W. J. Emery (2003), Further refinements to models for the bulk-skin sea surface temperature difference, J. Geophys. Res., 108(C12), 3377, doi:10.1029/2002JC001641.

Colbo, K., and R. Weller (2007), The variability and heat budget of the upper ocean under the Chile-Peru stratus, J. Mar. Res., 65(5), 607-637.

Colbo, K., and R. A. Weller (2009), Accuracy of the IMET sensor package in the Subtropics, J. Atmos. Oceanic Tech., 26(9), 1867-1890, doi:10.1175/2009JTECHO667.1. 


\section{PRYTHERCH ET AL.: OBSERVATIONS OF THE DIURNAL WARM LAYER}

Donlon, C. J., P. J. Minnett, C. Gentemann, T. J. Nightingale, I. J. Barton, B. Ward, and M. J. Murray (2002), Toward improved validation of satellite sea surface skin temperature measurements for climate research, $J$ Clim., 15(4), 353-369.

Fairall, C. W., E. F. Bradley, J. S. Godfrey, G. A. Wick, J. B. Edson, and G S. Young (1996a), Cool-skin and warm-layer effects on sea surface temperature, J. Geophys. Res., 101(C1), 1295-1308.

Fairall, C. W., E. F. Bradley, D. P. Rogers, J. B. Edson, and G. S. Young (1996b), Bulk parameterization of air-sea fluxes for Tropical OceanGlobal Atmosphere Coupled-Ocean Atmosphere Response Experiment, J. Geophys. Res., 101(C2), 3747-3764.

Fairall, C. W., E. F. Bradley, J. E. Hare, A. A. Grachev, and J. B. Edson (2003), Bulk parameterization of air-sea fluxes: Updates and verification for the COARE algorithm, J. Clim., 16, 571-591.

Farrar, J. T., C. J. Zappa, R. A. Weller, and A. T. Jessup (2007), Sea surface temperature signatures of oceanic internal waves in low winds, J. Geophys. Res., 112, C06014, doi:10.1029/2006JC003947.

Farrar, J. T., S. Lentz, J. Churchill, P. Bouchard, J. Smith, J. Kemp, J. Lord, G. Allsup, and D. Hosom (2009), King Abdullah University of Science and Technology (KAUST) mooring deployment cruise and fieldwork report, Tech. Rep. WHOI-KAUST-CTR-2009-02, 88 pp., Woods Hole Oceanogr. Inst., Woods Hole, Mass.

Fischer, A. S., R. A. Weller, D. L. Rudnick, C. C. Eriksen, C. M. Lee, K. H Brink, C. A. Fox, and R. R. Leben (2002), Mesoscale eddies, coastal upwelling, and the upper-ocean heat budget in the Arabian Sea, Deep Sea Res. Part II, 49(12), 2231-2264, doi:10.1016/S09670645(02)00036-X.

Gentemann, C. L., and P. J. Minnett (2008), Radiometric measurements of ocean surface thermal variability, J. Geophys. Res., 113, C08017, doi: 10.1029/2007JC004540.

Gentemann, C. L., C. J. Donlon, A. Stuart-Menteth, and F. J. Wentz (2003), Diurnal signals in satellite sea surface temperature measurements, Geophys. Res. Lett., 30(3), 1140, doi:10.1029/2002GL016291.

Gentemann, C. L., P. J. Minnett, and B. Ward (2009), Profiles of ocean surface heating $(\mathrm{POSH})$, A new model of upper ocean diurnal warming, $J$. Geophys. Res., 114, C07017, doi:10.1029/2008JC004825.

Hosom, D. S., R. A. Weller, R. E. Payne, and K. E. Prada (1995), The IMET (improved meteorology) ship and buoy systems, J. Atmos. Oceanic Tech., 12(3), 527-540.

Jiang, H., J. T. Farrar, R. C. Beardsley, R. Chen, and C. Chen (2009), Zona surface wind jets across the Red Sea due to mountain gap forcing along both sides of the Red Sea, Geophys. Res. Lett., 36, L19605, doi:10.1029/ 2009GL040008.

Kantha, L. H., and C. A. Clayson (1994), An improved mixed layer mode for geophysical applications, J. Geophys. Res., 99(C12), 25,235-25,266.

Kawai, Y., and H. Kawamura (2002), Evaluation of the diurnal warming of sea surface temperature using satellite-derived marine meteorological data, J. Oceanogr., 58(6), 805-814.

Kawai, Y., H. Kawamura, S. Tanba, K. Ando, K. Yoneyama, and N. Nagahama (2006), Validity of sea surface temperature observed with the TRITON buoy under diurnal heating conditions, J. Oceanogr., 62(6), 825-838.

Kennedy, J. J., P. Brohan, and S. F. B. Tett (2007), A global climatology of the diurnal variations in sea-surface temperature and implications for MSU temperature trends, Geophys. Res. Lett., 34, L05712, doi:10.1029/ 2006 GL028920.

Kondo, J., Y. Sasano, and T. Ishii (1979), On wind-driven current and temperature profiles with diurnal period in the oceanic planetary boundary layer, J. Phys. Oceanogr., 9(2), 360-372.

Large, W. G., J. C. McWilliams, and S. C. Doney (1994), Oceanic vertical mixing: A review and a model with a nonlocal boundary layer parameterization, Rev. Geophys., 32(4), 363-403, doi:10.1029/94RG01872.

Moyer, K. A., and R. A. Weller (1997), Observations of surface forcing from the subduction experiment: A comparison with global model products and climatological datasets, J. Clim., 10, 2725-2742.
Ohlmann, J. C. (2003), Ocean radiant heating in climate models, J. Clim., 16, 1337-1351.

Paulson, C. A., and J. J. Simpson (1981), The temperature difference across the cool skin of the ocean, J. Geophys. Res., 86, 11,044-11,504.

Price, J. F., R. A. Weller, and R. Pinkel (1986), Diurnal cycling: Observations and models of the upper ocean response to diurnal heating, cooling, and wind mixing, J. Geophys. Res., 91, 8411-8427.

Price, J. F., R. A. Weller, C. M. Bowers, and M. G. Briscoe (1987), Diurnal response of sea surface temperature observed at the long-term upper ocean study (34N, 70W) in the Sargasso Sea, J. Geophys. Res., 92(C13), $14,480-14,490$

Risien, C. M., and D. B. Chelton (2008), A global climatology of surface wind and wind stress fields from eight years of QuikSCAT scatterometer data, J. Phys. Oceanogr., 38, 2379-2413, doi:10.1175/2008JPO3881.1.

Saunders, P. M. (1967), The temperature at the ocean-air interface, $J$. Atmos. Sci., 24(3), 269-273.

Soloviev, A., and R. Lukas (2006), The Near-Surface Layer of the Ocean, pp. 572, Springer, Netherlands.

Soloviev, A., R. Lukas, and P. Hacker (2001), An approach to parameterization of the oceanic turbulent boundary layer in the western Pacific warm pool, J. Geophys. Res., 106(C3), 4421-4435.

Soloviev, A. V. (1982), On the vertical structure of the ocean thin surface layer at light wind, Dokl. Acad. Sci. USSR, Earth Sci. Sect., Engl. Transl., 18, 751-760.

Stommel, H., and A. H. Woodcock (1951), Diurnal heating of the surface of the Gulf of Mexico in the spring of 1942, Trans. AGU, 32, 565-571.

Stommel, H., K. Saunders, W. Simmons, and J. Cooper (1969), Observations of the diurnal thermocline, Deep Sea Res. Oceanogr. Abstr., 16, 269-284.

Stuart-Menteth, A. C., I. S. Robinson, and P. G. Challenor (2003), A global study of diurnal warming using satellite-derived sea surface temperature, J. Geophys. Res., 108(C5), 3155, doi:10.1029/2002JC001534.

Ward, B., R. Wanninkhof, W. R. McGillis, A. T. Jessup, M. D. DeGrandpre, J. E. Hare, and J. B. Edson (2004), Biases in the air-sea flux of $\mathrm{CO} 2$ resulting from ocean surface temperature gradients, J. Geophys. Res., 109, C08S08, doi:10.1029/2003JC001800.

Webster, P. J., C. A. Clayson, and J. A. Curry (1996), Clouds, radiation, and the diurnal cycle of sea surface temperature in the tropical Western Pacific, J. Clim., 9(8), 1712-1730.

Weller, R. A., and S. P. Anderson (1996), Surface meteorology and air-sea fluxes in the Western Equatorial Pacific warm pool during the TOGA Coupled Ocean-Atmosphere Response Experiment, J. Clim., 9, 19591990

Weller, R. A., D. L. Rudnick, R. E. Payne, J. P. Dean, N. J. Pennington, and R. P. Trask (1990), Measuring near-surface meteorology over the ocean from an array of surface moorings in the subtropical convergence zone, J. Atmos. Oceanic Tech., 7(1), 85-103.

Weller, R. A., M. F. Baumgartner, S. A. Josey, A. S. Fischer, and J. C. Kindle (1998), Atmospheric forcing in the Arabian Sea during 1994-1995 Observations and comparisons with climatologies and models, Deep Sea Res. Part II, 45, 1961-1999.

Weller, R. A., A. S. Fischer, D. L. Rudnick, C. E. Eriksen, T. D. Dickey, J. Marra, C. Fox, and R. Leben (2002), Moored observations of upper ocean response to the monsoon in the Arabian Sea during 1994-1995, Deep Sea Res. Part II, 49, 2195-2230.

Wick, G. A., J. C. Ohlmann, C. W. Fairall, and A. T. Jessup (2005), Improved oceanic cool skin corrections using a refined solar penetration model, J. Phys. Oceanogr., 35, 1986-1996, doi:10.1175/JPO2803.1.

Yu, L., and R. A. Weller (2007), Objectively analyzed airsea heat fluxes for the global ice-free oceans (19812005), Bull. Am. Meteorol. Soc., 88, 527-539, doi:10.1175/BAMS-88-4-527.

Yuter, S. E., and R. A. Houze (2000), The 1997 Pan American Climate Studies tropical Eastern Pacific process study. Part I, ITCZ region, Bull. Am. Meteorol. Soc., 81(3), 451-481. 